\title{
Personal radiofrequency electromagnetic field exposure measurements in Swiss adolescents
}

Katharina Roser ${ }^{1,2}$, Anna Schoeni ${ }^{1,2}$, Benjamin Struchen ${ }^{1,2}$, Marco Zahner ${ }^{3,4}$, Marloes Eeftens ${ }^{1,2}$, Jürg Fröhlich ${ }^{3,4}$ and Martin Röösli ${ }^{1,2, *}$

${ }^{1}$ Swiss Tropical and Public Health Institute, Socinstrasse 57, P.O. Box, 4002 Basel, Switzerland

${ }^{2}$ University of Basel, Petersplatz 1, 4003 Basel, Switzerland

${ }^{3}$ Institute for Electromagnetic Fields, Eidgenössische Technische Hochschule Zürich (ETH Zürich), Gloriastrasse 35, 8092 Zürich, Switzerland

${ }^{4}$ Fields at Work GmbH, Sonneggstrasse 60, 8006 Zürich, Switzerland

* Corresponding author

\section{Corresponding author:}

Martin Röösli

Swiss Tropical and Public Health Institute

Socinstrasse 57

P.O. Box

CH-4002 Basel

E-Mailmartin.roosli@unibas.ch

Tel. $\quad+41(0) 612848383$

Fax +41(0)612848501 


\section{Introduction}

Mobile phones and other wireless communication devices emitting radiofrequency electromagnetic fields (RF-EMF) are nowadays omnipresent and undergo a rapid development. In 2014, there were almost 7 billion mobile phone subscriptions worldwide, corresponding to $96 \%$ of the population (ICT 2015). In Switzerland, the number of mobile phone subscriptions reached 11.5 million in 2014 , what corresponded to $141 \%$ of the population (ICT 2015). The proportion of the world population covered by a $2 \mathrm{G}$ mobile phone network grew from 58\% in 2001 to $95 \%$ in 2015 and mobile internet access increased 12 times since 2007 reaching $47 \%$ of the population in 2015 (ICT 2015). Along that line, the ownership and use of wireless communication devices is growing. A recent representative survey in 1,086 adolescents aged between 12 and 19 years in Switzerland revealed that 98\% of the adolescents own a mobile phone, $76 \%$ a computer or laptop and $29 \%$ a tablet (Willemse et al. 2014). This development leads to ubiquitous exposure to RF-EMF in our everyday environment, but little is known about the extent of personal exposure to RF-EMF, in particular in adolescents. As a result, the current World Health Organization (WHO) research agenda for radiofrequency fields rates the quantification of personal exposures high priority (WHO 2010).

Adolescents spend most of their time at home and in school. Spot measurements of environmental RF-EMF in different European countries showed that exposure at home was mainly caused by mobile phone base stations and cordless phone (Digital Enhanced Cordless Telecommunications (DECT)) base stations (Breckenkamp et al. 2012; Tomitsch and Dechant 2015; Tomitsch et al. 2010; Verloock et al. 2014a; Verloock et al. 2014b; Vermeeren et al. 2013) or WLAN (Wireless Local Area Network) base stations (Breckenkamp et al. 2012). Main contributors to the environmental exposure in schools in Belgium and Greece were 
mobile phone base stations, radio broadcast transmitters and WLAN base stations (Verloock et al. 2014a; Verloock et al. 2014b; Vermeeren et al. 2013).

Data from spot measurements are useful to estimate exposure to RF-EMF in our everyday environments, but personal exposure to RF-EMF depends not only on exposure levels in different environments, but also on individual behaviours such as the use of wireless communication devices and time spent in various environments (Röösli et al. 2010). Personal measurements are measurement campaigns where volunteers carry a portable measurement device during their everyday life activities. Such measurements enable to measure at times and places representative of real-life situations.

Personal measurements in Europe were mainly conducted in adults (Bolte and Eikelboom 2012; Frei et al. 2009; Thomas et al. 2008a; Thuróczy et al. 2008; Valic et al. 2009; Viel et al. 2009); measurements in children and adolescents are scarce. Researchers in Hungary conducted in 2009 personal measurements in 31 school teachers as a proxy for children's exposure (Juhasz et al. 2011). In Slovenia, measurements in 18 children and adolescents (5-17 years) were performed in 2010/2011 (Valic et al. 2015) and in Germany, measurements in 1,524 adolescents (13-17 years) were conducted in 2006/2007 (Thomas et al. 2008b) . However, since then smartphones have been introduced and the use of wireless communication devices in this age group has changed tremendously. Measurements in Austria and Switzerland indicate that RF-EMF exposure in residential areas may have increased over the last few years (Tomitsch and Dechant 2015; Urbinello et al. 2014). Exposure to RF-EMF can be divided into two different types, the exposure from environmental sources such as broadcast transmitters, mobile phone base stations, cordless phone base stations, WLAN access points, and mobile phones in the surroundings (far-field), and the exposure from the use of wireless communication devices such as mobile phones, cordless phones and computer, laptops and tablets connected to WLAN (near-field). It is known that personal measurements may not adequately record the latter part of exposure, 
because measured values depend highly on the distance between the emitting source and the measurement device, which is not necessarily the same as the distance between the emitting source and the body (Bolte 2016; Inyang et al. 2008; Röösli et al. 2010). Thus, to obtain a comprehensive overview on the personal RF-EMF exposure, personal measurements need to be combined with dosimetric approaches that quantify absorbed RF-EMF by the body. The aim of this paper is to describe the personal RF-EMF exposure of Swiss adolescents in daily life and evaluate factors affecting personal exposure. Further, it is aimed to use personal measurements to estimate average contributions from far-field and near-field sources to the total absorbed RF-EMF dose by using a recently developed RF-EMF surrogate modelling approach (Roser et al. 2015a).

\section{Methods}

\section{HERMES study}

The HERMES (Health Effects Related to Mobile phonE use in adolescentS) study, a cohort study conducted in Central Switzerland, aims to prospectively investigate whether the exposure to RF-EMF emitted by mobile phones and other wireless communication devices causes behavioural problems and non-specific health disturbances or affects cognitive function in adolescents (Roser et al. 2015b; Roser et al. 2016; Schoeni et al. 2016; Schoeni et

al. 2015a; Schoeni et al. 2015b). The baseline investigation took place between June 2012 and March 2013; the follow-up investigation was conducted approximately one year later. The study participants filled in a paper and pencil questionnaire at school during school time supervised by two study managers. Participants could indicate whether they were willing to participate in the measurement study. Furthermore, paper and pencil questionnaires for the parents were distributed and they were asked to send these back directly to the study managers. 


\section{Personal measurements}

Personal measurements were conducted in a subgroup of the HERMES study participants. The participants of the personal measurements were selected so that they represented a broad range of the HERMES cohort according to basic criteria such as age, gender, school level and urbanization of home and school place. Data collection took place between May 2013 and April 2014. The instructions for the personal measurements were given at school. The participants were instructed to carry the portable measurement device, a so-called exposimeter, for three consecutive days. They were asked to carry the exposimeter in a padded hip bag if they were moving and to place it in their vicinity, but not directly on the body, when not moving. During the night, they were instructed to charge the exposimeter and place it on their bedside table or close to their bed but not directly on the floor.

Two versions of the ExpoM-RF exposimeter (the current version and a not commercialized prototype) were used to measure 12 frequency bands ranging from DVB-T (Digital Video Broadcasting - Terrestrial, centre frequency of $620 \mathrm{MHz}$ ) to ISM $2.4 \mathrm{GHz}$ (Industrial, Scientific and Medical 2.4 GHz, 2450 MHz) (Fields at Work 2015; Lauer 2011) with a measurement range of frequency specific lower reporting limits up to $5 \mathrm{~V} / \mathrm{m}$ (upper reporting limit; Table 1). The sum of them is referred to as total personal RF-EMF measurements (Table 1). The devices have the size of $16 \times 8 \times 3-5 \mathrm{~cm}$ and a weight of $300 \mathrm{~g}$. A sampling interval of 4 seconds was used. The devices were calibrated before the start of the measurements in January 2013, again in January 2014 and after the measurements in February 2015. Additionally, the participants kept a time-activity diary installed as an application on a smartphone provided by the study managers. The smartphone was operating in flight-mode to prevent influencing the measurements. The diary contained predefined locations categorized into home, school, outdoors, train, bus, car and various locations. During the measurement period, GPS coordinates were recorded by the diary smartphone. At the end of the measurement period, they filled in a short questionnaire on exposure relevant factors such as 
WLAN at home, ownership of mobile phone subscription or prepaid mobile phone and their mobile phone use during the measurement period (Table 2). Missing values in this questionnaire were imputed using answers to the same questions in the baseline or follow-up HERMES questionnaire whichever was temporally closer. The information about WLAN at school was obtained from the teacher or the head of the school during the school visit.

Ethical approval for the conduct of the study was received from the ethical committee of Lucerne, Switzerland on May 9, 2012.

\section{Table 1 about here}

\section{Data cleaning}

The personal measurement data were occasionally disrupted because of technical failures or because participants forgot to charge the device during night. We considered only those measurements which lasted at least 23 hours and which had corresponding diary entries available for analysis. Diaries were manually cleaned for implausible chronologies of diary entries (e.g. being at school followed by being at home without a period of outdoor, public transport or car in-between) using the smartphone-recorded GPS coordinates and visualisation of the paths and the measurements corresponding to the diary entries.

\section{Data analysis}

\section{Calculation of mean values}

The calculations were performed in power flux density unit $\left(\mu \mathrm{W} / \mathrm{m}^{2}\right)$. According to the sensitivity range specified by the manufacturer, measurements were left censored at the frequency specific lower reporting limit and right censored at $5 \mathrm{~V} / \mathrm{m}$ (upper reporting limit; Table 1). 
Total refers to the sum of the frequency bands listed in Table 1, Uplink (RF-EMF emitted from mobile phone handsets) to the sum of the uplink frequency bands Uplink 900, Uplink 1800 and Uplink 1900, and Downlink (RF-EMF emitted from mobile phone base stations) to the sum of the downlink frequency bands Downlink 900, Downlink 1800 and Downlink 2100 (see Table 1 for exact definitions of frequencies).

To account for interruption of measurements (e.g. from lack of charging), we calculated for each participant the average exposure for 6 time slots ( 5 time slots during daytime: 06:0007:59, 08:00-11:59, 12:00-13:59, 14:00-16:59, 17:00-21:59, 1 time slot for night-time: 22:0005:59). Mean exposure for the whole measurement period was then calculated as timeweighted average of these time slots. Mean exposure for the day refers to the time-weighted average of the 5 daytime slots. Mean exposure for workdays was calculated in the same way as the mean exposure for the whole measurement period but taking into account only measurements on workdays, the same was applied for the weekend exposure. If for one day a time slot was missing, a time-weighted average was calculated with adjusted weights. Measurements with more than one missing time slot or missing night measurements were excluded. Mean exposure for the locations home, school, outdoors, train, bus, car and various locations was calculated taking into account all available measurements per participant at these locations according to their time-activity diary.

\section{Evaluation of possibly exposure related factors}

To address factors possibly affecting personal RF-EMF measurements, we compared the measurements of adolescents with and without WLAN at school and at home, respectively as well as the impact of switching off the WLAN modem at home during the night. Regarding mobile phone use, we evaluated the impact of having a subscription or using a prepaid mobile phone, reporting to switch off the mobile phone during the night and the use of internet on the mobile phone (with and without WLAN). 


\section{Sensitivity analyses}

A sensitivity analysis was conducted to evaluate the impact of the manual diary cleaning on the study results by conducting analyses with and without corrected diary entries.

The adjacent Downlink 1800, DECT and Uplink 1900 bands are a challenge for personal RFEMF exposimeters because cross-talk occurs between these bands (Lauer et al. 2012). To correct values for potential cross-talk, a data-driven correction algorithm was developed (manuscript in preparation). The development of the algorithm was based on personal measurements in 115 Swiss adolescents and adults. First, distinct exposure windows with similar exposure patterns were defined. Within these exposure windows, the correlations between DECT measurements and the $1800 \mathrm{MHz}$ base station signal (Downlink 1800) and the $1900 \mathrm{MHz}$ mobile phone handset signal (Uplink 1900), respectively were calculated. If the correlations were above a defined threshold value, it was corrected for cross-talk within the respective window. The ratio between the respective two signals was used to decide on the direction of the cross-talk. The median of the exposure during the corresponding location was used to substitute the affected values. A sensitivity analysis was conducted with this correction algorithm to assess the impact of this correction on the results of the personal measurements.

\section{Use of personal measurements for dose estimations}

Using the average exposures measured during the personal measurements, we applied a recently developed RF-EMF dose modelling approach (Roser et al. 2015a) that combines the exposure from near-field and far-field RF-EMF sources to put the personal measurements in the context of dose calculations for a typical (average) HERMES participant. The far-field component aggregates the measured or modelled exposure from environmental sources such as radio and television (TV) broadcast transmitters, mobile phone base stations, cordless phone base stations, WLAN access points as well as other people's mobile phones to a RF- 
EMF dose estimate using specific absorption rates (SAR) from the literature (Lauer et al. 2013). A short description can be found in the Supplementary Material. For TV broadcast, mobile phone base stations, DECT and WLAN base stations we used the average of all personal measurements. The radio FM (Frequency Modulation) broadcasting band was not yet included in the prototype version of the ExpoM-RF and thus time-weighted average modelled exposure at home and in school of the participants was used instead (Bürgi et al. 2010; Bürgi et al. 2008). To estimate the contribution of uplink exposure from other people's mobile phones (far field), we used the mean uplink measurements of all participants that reported not to use mobile internet on their mobile phone, because their personal measurements are less affected by own mobile phone use. Note that all participants owned a mobile phone.

The near-field component of the dose model assesses RF-EMF dose from the use of wireless communication devices (mobile phones, cordless phones, computers, laptops and tablets connected to WLAN) by combining the duration of wireless device use with literature derived SAR values for the brain and the whole body for each of these exposure situations (Gati et al. 2009; Hadjem et al. 2010; Huang Y. June 8-13, 2014; Lauer et al. 2013; Persson et al. 2012; SEAWIND Sound Exposure \& Risk Assessment of Wireless Network Devices Final Summary Report 2013).

To obtain the wireless device use durations of a typical HERMES participant we used the wireless device use data of the whole HERMES cohort. For estimating average own mobile phone use in the sample, we used average operator-recorded call duration of all HERMES participants who gave consent to provide their data. For data traffic on the mobile phone and the use of computer, laptop and tablet with WLAN, the mean duration was obtained from the written HERMES questionnaire of all study participants. For the duration of DECT phone calls, the same duration as for mobile phone calls was assumed. This resulted in the typical HERMES participant with the following communication device use each day: $1.85 \mathrm{~min}$ 
mobile phone and DECT phone calls, 11.5 min of mobile phone data traffic via network and 30.6 min via WLAN, 57.6 min of computer, laptop and tablet use while connected to WLAN and having the mobile phone $4.42 \mathrm{~h}$ close to the body assuming stand-by data traffic of the mobile phone close to the body for this time period.

\section{Results}

\section{Personal measurements}

From 439 students who participated in the baseline investigation of the HERMES study, 221 $(50.3 \%)$ volunteered to participate in the personal measurement study (Figure 1). Thereof 121 adolescents were selected for participation in the personal measurements and 101 out of these 121 measurement sequences had at least 23 hours of measurements and corresponding diary entries. Thereof 95 had a diary of sufficient quality to attribute measurements to locations. Five of these sets had more than one missing time slot and were excluded. This resulted in 90 measurements included in the analysis. The personal measurements lasted on average 72.3 hours ( $\mathrm{SD}=21.7$ hours, range: $23.0-121.2$ hours) and 62,710 (range: $21,455-112,653$ ) single measurements per participant were recorded. A subsample of 38 out of the 90 measurement sequences had measurements on both workdays and weekend days available and was used for the comparison of workdays and weekend measurements.

\section{Figure 1 about here}

\section{Characteristics of study participants}

The mean age of the participants was 15.1 years and 57 (63.3\%) participants were female (Table 2). The majority (90.0\%) had Swiss nationality. Thirty-four participants attended a school with WLAN, 86 had WLAN at home and thereof, 61 reported not to switch off their WLAN modem at home during the night. 
All participants owned a mobile phone at the time of the personal measurements and most of these devices $(94.4 \%)$ were smartphones. About half of the participants $(45.6 \%)$ had a mobile phone subscription with a mobile phone operator; the others used prepaid mobile phones. A quarter $(26.7 \%)$ indicated to switch off their mobile phone during the night. Of the 83 participants using mobile internet on their mobile phone, $83.1 \%$ regularly used WLAN for that connection. According to $\chi^{2}$ test statistics, the participants of the personal measurements were comparable to the HERMES follow-up cohort $(n=425)$ according to age, sex, school level, WLAN at school and at home, owning a mobile phone or a smartphone and mobile phone use except that more Swiss adolescents were included ( $\mathrm{p}$-value $=0.01)$ and less participants had a mobile phone subscription $(\mathrm{p}$-value $=0.01)($ Table 2$)$.

\section{Table 2 about here}

\section{Mean exposure and contribution of different RF-EMF sources}

Total personal RF-EMF measurements were on average $63.2 \mu \mathrm{W} / \mathrm{m}^{2}(0.15 \mathrm{~V} / \mathrm{m})$. Median total RF-EMF measurements were considerably lower $\left(25.5 \mu \mathrm{W} / \mathrm{m}^{2}\right.$, Table 3$)$ reflecting the highly skewed data distribution (Figure S1 in Supplementary Material). The exposure from mobile phones (uplink) contributed most (67.2\% of total RF-EMF) (Table 3 and Figure 2). Exposure from fixed site transmitters contributed $26.5 \%$ (downlink: $19.8 \%$, TV broadcast transmitters: 6.7\%). WLAN exposure accounted on average for $3.5 \%$ and DECT exposure for $1.3 \%$. Uplink 900 and downlink 900 contributed most to average uplink and downlink exposure, respectively.

\section{Table 3 about here}

Figure 2 about here

\section{Personal measurements at different locations}

Regarding different locations, adolescents' average total personal RF-EMF measurements were highest when spending time in public transport and cars $\left(839.4 \mu \mathrm{W} / \mathrm{m}^{2}\right.$ in cars, 
676.3 $\mu \mathrm{W} / \mathrm{m}^{2}$ in buses and $537.1 \mu \mathrm{W} / \mathrm{m}^{2}$ in trains) (Figure 3 and Tables $\mathrm{S} 1$ and $\mathrm{S} 2$ in Supplementary Material). The lowest measurements were measured at school $\left(59.6 \mu \mathrm{W} / \mathrm{m}^{2}\right)$ and at home $\left(31.1 \mu \mathrm{W} / \mathrm{m}^{2}\right)$.

\section{Figure 3 about here}

\section{WLAN in school and at home}

The presence of a WLAN at school and WLAN at home had little impact on average WLAN measurements (Figure 4 and Tables S3 and S4 in Supplementary Material). Participants attending a school with WLAN (34 participants (Table 2) consisting of 32 adolescents having WLAN at home and at school and two adolescents having WLAN at school but not at home) had slightly higher mean WLAN exposure than participants without WLAN at their school $\left(2.9 \mu \mathrm{W} / \mathrm{m}^{2}\right.$ vs. $\left.1.5 \mu \mathrm{W} / \mathrm{m}^{2}\right)$. If the comparison was restricted to the measurements taken in the school, the difference was somewhat larger $\left(7.4 \mu \mathrm{W} / \mathrm{m}^{2}\right.$ vs. $\left.1.0 \mu \mathrm{W} / \mathrm{m}^{2}\right)$. Only four participants had no WLAN at home (thereof two had WLAN at school). Overall their mean WLAN measurements were higher $\left(6.0 \mu \mathrm{W} / \mathrm{m}^{2}\right)$ than for the other two groups. However, their WLAN measurements at home were indeed minimal $\left(0.02 \mathrm{~W} / \mathrm{m}^{2}\right)$.

Participants, who reported not to switch off WLAN modem at home during night, had higher WLAN measurements at home compared to the participants who switched off WLAN at home $\left(0.9\right.$ vs. $\left.0.4 \mu \mathrm{W} / \mathrm{m}^{2}\right)$. For the whole measurement period, the WLAN measurements were increased as well (2.6 vs. $\left.0.7 \mu \mathrm{W} / \mathrm{m}^{2}\right)$.

\section{Figure 4 about here}

\section{Mobile phone use related factors}

Figure 5 demonstrates that the own mobile phone has a substantial impact on personal uplink measurements (see Tables S5 and S6 in Supplementary Material for details). For instance, participants with a subscription had higher uplink measurements compared to those using prepaid mobile phones (78.0 vs. $\left.12.8 \mu \mathrm{W} / \mathrm{m}^{2}\right)$. The use of internet by mobile phone was 
associated with higher uplink measurements as well $\left(45.3\right.$ vs. $\left.8.9 \mu \mathrm{W} / \mathrm{m}^{2}\right)$. Those stating not to use WLAN by mobile phone had higher uplink measurements compared to those who used WLAN (68.1 vs. $40.7 \mu \mathrm{W} / \mathrm{m}^{2}$ ), but strikingly, the difference in WLAN measurements was marginal between these two groups ( 2.7 vs. $\left.2.3 \mu \mathrm{W} / \mathrm{m}^{2}\right)$.

\section{Figure 5 about here}

\section{Diurnal variation of personal measurements}

Total RF-EMF measurements were clearly increased during daytime compared to night-time (80.8 vs. $28.1 \mu \mathrm{W} / \mathrm{m}^{2}$ ) (Figure 6 and Tables S7 and S8 in Supplementary Material).

For $38(42.2 \%)$ participants we had measurements on workdays and on weekend days available. For those, mean RF-EMF measurements were slightly higher on weekend days compared to workdays (57.3 vs. $\left.51.0 \mu \mathrm{W} / \mathrm{m}^{2}\right)$. The diurnal pattern was similar on workdays and on weekends, total measurements increased with progressing time of the day (Figure 7 and Table S9 in Supplementary Material).

\section{Figure 6 about here}

Figure 7 about here

\section{Use of personal measurements for dose estimations}

Using the recently developed RF-EMF exposure surrogate (Roser et al. 2015a) and the personal measurements, the daily dose for different exposure sources was calculated for the typical (average) HERMES participant (Figures 8 and 9 and Table S10 in Supplementary Material).

Far-field exposure contributed $6.0 \%$ to the brain dose and $9.0 \%$ to the whole body dose. The most relevant far-field contributor was downlink with $2.6 \%$ for the brain and $3.9 \%$ for the whole body dose. WLAN contributed on average $0.2 \%$ to the brain dose and $0.4 \%$ to the whole body dose. Using the mobile phone for calls was the most relevant contributor to the average brain RF-EMF dose (77.0\%). For the whole body dose mobile phone calls 
contributed $23.6 \%$, data transmission via mobile phone network $7.0 \%$ and data transmission via WLAN $18.7 \%$. Carrying a mobile phone on the body in stand-by mode contributed $1.6 \%$. The use of WLAN by computers, laptops and tablets contributed $35.2 \%$ to the whole body dose.

\section{Figure 8 about here}

Figure 9 about here

\section{Sensitivity analyses}

\section{Diary cleaning}

In a sensitivity analysis, we compared our results with an analysis based on a dataset with original (uncleaned) diary entries. This analysis showed that diary cleaning is relevant for locations and activities with short durations (train and bus), whereas measurements with long durations (home and school) were barely affected (Table S11 in Supplementary Material). These differences were driven by changes in the uplink and to a lesser extent by downlink measurements.

\section{DECT correction algorithm}

The applied DECT correction algorithm reduced the average DECT measurements by a factor of 5.8 (Table S12 in Supplementary Material). Since DECT measurements were a small part of the total measurements ( $1.3 \%$ on average), reduction factor was small for the total measurements (factor of 1.1) and the contribution of the different sources to the total exposure did change only minimally (63.2\% vs. $67.2 \%$ for uplink, $18.7 \%$ vs. $19.8 \%$ for downlink, $3.2 \%$ vs. $3.5 \%$ for WLAN, $6.3 \%$ vs. $6.7 \%$ for TV and $7.1 \%$ vs. $1.3 \%$ for DECT). Regarding different locations reduction factors were highest in buses and cars (36.8 and 15.0, respectively). For details see Tables S13, S14, S15 and S16 in Supplementary Material. 


\section{Discussion}

Main contributors to the personal RF-EMF measurements of our study participants were mobile phones (uplink) followed by mobile phone base stations (downlink). Uplink was particularly high in adolescents using the internet on their mobile phone. The mean contribution from WLAN exposure was low, even for adolescents having WLAN at school and at home. Using personal measurements and combining them with data on the usage of wireless devices for a comprehensive dose calculation of the typical HERMES participant revealed that far-field sources contributed $6.0 \%$ to the total RF-EMF dose of the brain and $9.0 \%$ to the whole body dose, whereas $94 \%$ and $91 \%$ of the total RF-EMF dose of the brain the whole body, respectively originated from near-field sources.

\section{Comparison with other studies}

The prototype version of the ExpoM-RF used in this measurement study does not measure radio FM (88 - $108 \mathrm{MHz})$ broadcasting as done in most other previous studies. However, on average, radio FM is a small contributor in our study (on average $1.7 \mu \mathrm{W} / \mathrm{m}^{2}$ at home and $0.8 \mu \mathrm{W} / \mathrm{m}^{2}$ in school according to geospatial propagation modelling for the HERMES cohort) and thus, in the following paragraph, our measurements are compared with other personal measurement studies that had included radio FM.

Measured personal total RF-EMF exposure varied across studies, ranging from $21.5 \mu \mathrm{W} / \mathrm{m}^{2}$ in German children to $180 \mu \mathrm{W} / \mathrm{m}^{2}$ in Dutch adults (Bolte and Eikelboom 2012; Frei et al. 2009; Thomas et al. 2008a; Thomas et al. 2008b; Thuróczy et al. 2008; Valic et al. 2015; Viel et al. 2009) (Table 4). These discrepancies may be explained by different study populations (children, adolescents and adults), different measurement devices, diverse data processing (for instance dealing with measurements below the reporting limit of the devices) and different study settings (place and time). The most comparable study in terms of study population is the German measurement study in 1,524 adolescents in 2006/2007 (Thomas et al. 2008b), in 
which measured total exposure for uplink, downlink, DECT and WLAN was $24.0 \mu \mathrm{W} / \mathrm{m}^{2}$ during waking hours which is considerably lower compared to the mean daytime measurements for the same frequency bands in our study $\left(75.5 \mu \mathrm{W} / \mathrm{m}^{2}\right)$. However, at that time smartphones were not yet available and the use of mobile internet, the most relevant exposure factor in our study, was not an issue. Our small sample of 7 participants not using mobile internet had a mean exposure of $31.5 \mu \mathrm{W} / \mathrm{m}^{2}$, which is similar to the German study. In newer studies in adults, higher exposure levels were measured: $130 \mu \mathrm{W} / \mathrm{m}^{2}$ in Switzerland (Frei et al. 2009) and $180 \mu \mathrm{W} / \mathrm{m}^{2}$ in the Netherlands (Bolte and Eikelboom 2012) compared to 63.2 $\mu \mathrm{W} / \mathrm{m}^{2}$ in our study. These measurements were done in adults and in mostly urban areas, whereas our study area mainly consisted of rural places. In addition, lower exposure levels in schools for adolescents compared to workplaces for adults may contribute to the lower exposure levels in our study.

We found uplink and downlink being the dominant sources $(67.2 \%$ and $19.8 \%$ of the total exposure in our study). In other personal measurement studies contribution of different sources was distributed more equally (Bolte and Eikelboom 2012; Frei et al. 2009; Thuróczy et al. 2008; Viel et al. 2009). Possible explanations for this discrepancy may include low network coverage in our rural study area and longer mobile internet use in adolescents compared to adults.

\section{Table 4 about here}

\section{Measurements at different locations and times}

Our finding of high measurement values when travelling $\left(537.1 \mu \mathrm{W} / \mathrm{m}^{2}\right.$ in trains, $676.3 \mu \mathrm{W} / \mathrm{m}^{2}$ in buses and $839.4 \mu \mathrm{W} / \mathrm{m}^{2}$ in cars in our study) confirms previous results although some variations in levels have been observed in different studies; for instance for the exposure in trains: $1,160 \mu \mathrm{W} / \mathrm{m}^{2}$ in a Swiss measurement study (Frei et al. 2009), $354 \mu \mathrm{W} / \mathrm{m}^{2}$ in the Netherlands (Bolte and Eikelboom 2012) and $175 \mu \mathrm{W} / \mathrm{m}^{2}$ in France (Viel et al. 2009). 
Measurements at home $\left(31.1 \mu \mathrm{W} / \mathrm{m}^{2}\right.$ in our study) were in general lower compared to previous personal measurement studies (levels of $172 \mu \mathrm{W} / \mathrm{m}^{2}$ (Bolte and Eikelboom 2012), $100 \mu \mathrm{W} / \mathrm{m}^{2}$ (Frei et al. 2009) and $106.2 \mu \mathrm{W} / \mathrm{m}^{2}$ (Viel et al. 2009)). Since personal measurements in children and adolescents are rare, reported levels in schools are scarce. Mean measurements of $59.6 \mu \mathrm{W} / \mathrm{m}^{2}$ in our study were much lower than levels of spot measurements in schools in Belgium and Greece (325.2 to $424.7 \mu \mathrm{W} / \mathrm{m}^{2}$ ) (Verloock et al. 2014a; Vermeeren et al. 2013). Note that these spot measurements intended to assess highest values, whereas personal measurements represent typical values.

Slightly increased exposure at weekend compared to workdays $(+12 \%$ in mean measurements) and clearly decreased exposure during night-time compared to daytime (-65\% in mean measurements) was observed in other personal measurement studies as well (Bolte and Eikelboom 2012; Frei et al. 2009; Viel et al. 2009). Personal measurements conducted by researchers in Belgium using 28 predefined exposure scenarios also found that uplink and DECT measurements were clearly decreased during night-time compared to daytime (Joseph et al. 2008). Increased exposure during afternoon hours compared to morning hours was found in German children and adolescents as well (Thomas et al. 2008b), whereas in German adults no difference in exposure for morning and afternoon hours was observed (Thomas et al. 2008a). A similar diurnal pattern of increasing exposure with progressing time of the day was also observed in Dutch adults (Bolte and Eikelboom 2012).

\section{DECT measurements}

Average DECT measurements in our sample $\left(0.8 \mu \mathrm{W} / \mathrm{m}^{2}\right)$ were considerably lower compared to personal measurements in Switzerland in 2007 (29.5 $\mu \mathrm{W} / \mathrm{m}^{2}$ (Frei et al. 2009)), but comparable to measurements in France in 2006 (3.6 $\mu \mathrm{W} / \mathrm{m}^{2}$ (Viel et al. 2009)) using both EME Spy 120 devices (SATIMO, France). Part of the difference in the measurements in Switzerland can be explained by the fact that the previously used measurement device EME 
Spy 120 overestimated DECT measurements (Lauer et al. 2012). Another reason for the lower DECT exposure may be the introduction of eco mode DECT phones. Eco mode phones emit only if they are used for calls, whereas conventional DECT phones also emit RF-EMF in stand-by mode. This explanation is in line with a spot measurement survey in Austrian households (Tomitsch and Dechant 2015). They found a 60\% reduction in mean DECT exposure between 2006 and 2012 and a mean DECT exposure of $3.0 \mu \mathrm{W} / \mathrm{m}^{2}$ for households without DECT phone or an eco mode DECT phone compared to $420.7 \mu \mathrm{W} / \mathrm{m}^{2}$ for households with a conventional DECT phone (Tomitsch and Dechant 2015).

\section{WLAN measurements}

Our WLAN measurements (on average $2.2 \mu \mathrm{W} / \mathrm{m}^{2}$ ) were similar to personal measurements in Switzerland (5.3 $\mu \mathrm{W} / \mathrm{m}^{2}$ (Frei et al. 2009)) and Germany (1.1 $\mu \mathrm{W} / \mathrm{m}^{2}$ (Thomas et al. 2008a)) between 2005 and 2008.

We found WLAN at school and at home having minor impact on personal exposure. There is a public debate whether schools should install WLAN in their buildings. Our measurements demonstrate that this exposure source is of minor relevance compared to other RF-EMF sources. Attending a school with or without WLAN yields $0.2 \%$ difference in total whole body RF-EMF dose, and similarly, the impact of switching off WLAN at home during night is minor ( $0.2 \%$ of whole body dose). Measurements in Austrian households found a more pronounced difference in WLAN exposure for households with WLAN compared to those without or switched off WLAN base station (68.9 vs. $\left.2.7 \mu \mathrm{W} / \mathrm{m}^{2}\right)$. However, they did not measure average exposure but intended to measure the highest value at bedside (Tomitsch and Dechant 2015).

\section{Uplink measurements}

Uplink measurements were on average $42.5 \mu \mathrm{W} / \mathrm{m}^{2}$ in our study. 
Our results indicate that mainly using the internet on the mobile phone increases personal uplink measurements. For the participants using mobile internet, mean uplink measurements ranged from 0.1 to $664.9 \mu \mathrm{W} / \mathrm{m}^{2}$; for the remaining 7 participants not using internet on the mobile phone uplink exposure ranged from 0.7 to $17.7 \mu \mathrm{W} / \mathrm{m}^{2}$.

Although, in principle it is not possible to disentangle the contribution of the uplink exposure caused by the own mobile phone compared to the exposure from other people's mobile phones, our comparison of mobile internet users and non-users clearly demonstrates that the own mobile phone plays a considerable role for personal uplink measurements. In a previous Swiss study the difference of personal uplink measurements between people with and without a mobile phone was small (42 vs. $20 \mu \mathrm{W} / \mathrm{m}^{2}$ (Frei et al. 2009)) leading to the conclusion, that personal mobile phone use contributed relatively little to the personal measurements (Frei et al. 2010). Since then, type of mobile phones has changed remarkably and $94 \%$ of our measurement study participants owned a smartphone. These participants reported to use their mobile phone on average 12 minutes per day for internet use via mobile phone network and 31 minutes per day for internet use via WLAN. In addition, emissions in stand-by mode may also be relevant as it was observed in a measurement study investigating exposure from mobile phones in stand-by mode when travelling (Urbinello and Röösli 2013).

\section{Use of personal measurements for dose estimations}

The dose calculation integrating near-field and far-field sources clearly demonstrates that the RF-EMF exposure of adolescents is mainly driven by the use of wireless devices close to the body. For the typical HERMES participant, $94.0 \%$ of the brain and $91.0 \%$ of the whole body dose originated from wireless device use. Far-field sources are thus less relevant. For instance, the brain dose of the average downlink exposure during 24 hours corresponds to a GSM (Global System for Mobile Communications, here Uplink 900 or Uplink 1800) mobile phone call duration of $2.6 \mathrm{~s}$ and an UMTS (Universal Mobile Telecommunications System, 
here Uplink 1900) call duration of $6.1 \mathrm{~min}$. For the whole-body dose, $15.0 \mathrm{~s}$ GSM and 34.2 min UMTS call duration correspond to the mean downlink exposure of one day. This demonstrates that precautionary measures to reduce far-field exposure sources have limited impact on the exposure situation of adolescents. However, the type of network (GSM, UMTS or WLAN) and the connection quality interacts with the mobile phone and determines its output power. Thus, from a precautionary point of view, to efficiently reduce exposure, one should more systematically investigate, which measures are most relevant to reduce RF-EMF emissions of wireless devices, in particular when browsing the internet since this is often done by adolescents. The potential of such measures is exemplarily demonstrated in our measurement study by the fact that mean uplink measurements were decreased, whereas mean WLAN measurements were not increased for participants who reported to regularly use WLAN on their mobile phone compared to those who do not use WLAN for mobile internet. Obviously, dose calculations are subject to uncertainty, but nevertheless, this approach is considered useful to combine exposure from near-field and far-field sources to one exposure surrogate.

\section{Strengths and limitations of personal measurements}

Personal measurements allow investigating the exposure during all activities of everyday life of adolescents. Thus, measured exposure is assumed to represent true exposure taking into account individual behaviour (Röösli et al. 2010). However, personal measurements also have limitations. They are costly, time-consuming and ask for a big effort from the participants. This often results in a relatively small study sample as in our study (90 adolescents out of 439 HERMES participants). Furthermore, selection bias may be of concern since adolescents who are willing to make the effort to participate may be different from non-participants. However, our participants were comparable to the HERMES follow-up cohort expect regarding nationality and having a mobile phone subscription. Since we found having a mobile phone 
subscription associated with higher uplink measurements the considerable contribution of the uplink exposure on the total RF-EMF exposure may be even underestimated.

We were not able to control the positioning of the exposimeters during the personal measurements. However, we instructed the participants in person and in detail about how to handle the exposimeter during the measurements. Furthermore, we provided detailed information sheets and the participants had the possibility to contact us at any time during the measurements in the case of uncertainties or questions.

Other limitations come with body worn exposimeters per se; cross-talk between adjacent frequency bands, interference of measurements by the body (body shielding) and the use of wireless communication devices operating close to the body.

Cross-talk occurs if emitted power in one frequency band is measured and reported in another band. Of particular concern is cross-talk concerning the DECT band $(1880-1900 \mathrm{MHz})$ which is narrow and adjoins the downlink $1800(1805-1880 \mathrm{MHz})$ and the uplink 1900 (1920 - $1980 \mathrm{MHz}$ ) bands (Lauer et al. 2012). We approached that problem in a sensitivity analysis applying a DECT correction algorithm. The correction resulted in $82.6 \%$ decrease in average DECT exposure and 6.1\% decrease in total exposure (Table S11 in Supplementary Material). Changes in the contribution of the different sources were minor.

Body shielding arises if the body is between the RF-EMF emitting source and the exposimeter. For one single measurement, shielding can reduce the measurement by a factor 10 or even higher (Blas et al. 2007; Iskra et al. 2010). However, for average exposure, the situation is less dramatic. Numerical simulations (Gryz et al. 2015; Iskra et al. 2010; Neubauer et al. 2010) and test measurements (Bolte et al. 2011) have shown that underestimation depends on the type of measurement device, on the frequency band, on the position of the measurement device on the body and on human shape and was up to $50 \%$ in total. We instructed the participants to place the exposimeter in their vicinity, but not directly 
on the body, when not moving. Thus, in our study body shielding mostly affects the measurements taken during travel.

Another limitation of personal measurements with exposimeters is the assessment of the exposure from wireless communication devices operating close to the body (Bolte 2016; Inyang et al. 2008; Röösli et al. 2010). To deal with that challenge, we combined the personal measurements with a recently developed exposure surrogate combining exposure from environmental sources with exposure from the use of devices (Roser et al. 2015a), a unique feature of our study.

Our measurement study was conducted in a rural area; thus, our results might not be generalizable to urban areas and adolescent populations in other countries. Therefore, more measurement studies in this age population covering a larger variety of urbanization degree are needed.

\section{Conclusions}

Our results indicate that the main contributor to total RF-EMF measurements of adolescents is their mobile internet use on the mobile phone. For those not using the mobile internet, downlink is most relevant. WLAN at school and at home have minor impact on personal RFEMF measurements. By combining personal measurements with dose calculations from the use of wireless communication devices close to the body, we were able to demonstrate that the exposure from environmental sources plays a minor role compared to the use of wireless communication devices. In conclusion, in our study of 90 adolescents living in primarily rural areas of Switzerland we did not find any indication that adolescents are highly exposed to RFEMF despite their frequent wireless device use. 


\section{Acknowledgements}

The HERMES study is funded by the Swiss National Science Foundation (project number 138190). This research is also supported by the Swiss Research Foundation for Electricity and Mobile Communication (reference number 41) and Benjamin Struchen is supported by a FP7ENV-2013 grant (Grant Agreement 603794, 2014-2018) for the project GERoNiMO Generalised EMF Research using Novel Methods - an integrated approach: from research to risk assessment and support to risk management. Many thanks go to the study participants and their parents for participating in the HERMES study.

\section{References}

Blas J, Lago FA, Fernandez P, Lorenzo RM, Abril EJ (2007) Potential exposure assessment errors associated with body-worn RF dosimeters Bioelectromagnetics 28:573-576 doi:10.1002/bem.20355

Bolte JF (2016) Lessons learnt on biases and uncertainties in personal exposure measurement surveys of radiofrequency electromagnetic fields with exposimeters Environ Int 94:724-735 doi:10.1016/j.envint.2016.06.023

Bolte JF, Eikelboom T (2012) Personal radiofrequency electromagnetic field measurements in The Netherlands: exposure level and variability for everyday activities, times of day and types of area Environ Int 48:133-142 doi:10.1016/j.envint.2012.07.006

Bolte JF, van der Zande G, Kamer J (2011) Calibration and uncertainties in personal exposure measurements of radiofrequency electromagnetic fields Bioelectromagnetics 32:652663 doi:10.1002/bem.20677

Breckenkamp J, Blettner M, Schuz J, Bornkessel C, Schmiedel S, Schlehofer B, BergBeckhoff G (2012) Residential characteristics and radiofrequency electromagnetic field exposures from bedroom measurements in Germany Radiat Environ Biophys 51:85-92 doi:10.1007/s00411-011-0389-2

Bürgi A, Frei P, Theis G, Mohler E, Braun-Fahrländer C, Fröhlich J, Neubauer G, Egger M, Röösli M (2010) A model for radiofrequency electromagnetic field predictions at outdoor and indoor locations in the context of epidemiological research Bioelectromagnetics 31:226-236 doi:10.1002/bem.20552

Bürgi A, Theis G, Siegenthaler A, Röösli M (2008) Exposure modeling of high-frequency electromagnetic fields J Expo Sci Environ Epidemiol 18:183-191 doi:10.1038/sj.jes.7500575

Fields at Work (2015) ExpoM-RF User Manual (version 2.1). http://www.fieldsatwork.ch/uploads/Downloads/Expom_RF_Manual-EN_v2.1.pdf

Frei P, Mohler E, Bürgi A, Fröhlich J, Neubauer G, Braun-Fahrlander C, Röösli M (2010) Classification of personal exposure to radio frequency electromagnetic fields (RFEMF) for epidemiological research: Evaluation of different exposure assessment methods Environ Int 36:714-720 doi:10.1016/j.envint.2010.05.005 
Frei P, Mohler E, Neubauer G, Theis G, Bürgi A, Fröhlich J, Braun-Fahrländer C, Bolte J, Egger M, Röösli M (2009) Temporal and spatial variability of personal exposure to radio frequency electromagnetic fields Environ Res 109:779-785 doi:10.1016/j.envres.2009.04.015

Gati A, Hadjem A, Man-Fai W, Wiart J (2009) Exposure induced by WCDMA mobiles phones in operating networks IEEE Trans Wireless Commun 8:5723-5727 doi:10.1109/TWC.2009.12.080758

Gryz K, Zradzinski P, Karpowicz J (2015) The role of the location of personal exposimeters on the human body in their use for assessing exposure to the electromagnetic field in the radiofrequency range $98-2450 \mathrm{MHz}$ and compliance analysis: evaluation by virtual measurements Biomed Res Int 2015:272460 doi:10.1155/2015/272460

Hadjem A, Conil E, Gati A, Wong M-F, Wiart J (2010) Analysis of power absorbed by children's head as a result of new usages of mobile phone IEEE Trans Electromagn Compat 52:812-819

Helsel DR (2005) Nondetects and Data Analysis: Statistics for Censored Environmental Data. Wiley-Interscience,

Huang Y. CE, Wiart J., Varsier N., Person C. (June 8-13, 2014) Sensitivity analysis of downlink received and uplink emitted powers in a geographical area to ICT usage parameters. Paper presented at the Proceedings of the Annual Meeting of BEMS and EBEA, Capetown, South Africa,

ICT (2015) ICT Facts \& Figures. The world in 2015. http://www.itu.int/en/ITUD/Statistics/Documents/facts/ICTFactsFigures2015.pdf

Inyang I, Benke G, McKenzie R, Abramson M (2008) Comparison of measuring instruments for radiofrequency radiation from mobile telephones in epidemiological studies: implications for exposure assessment J Expo Sci Environ Epidemiol 18:134-141 doi:10.1038/sj.jes.7500555

Iskra S, McKenzie R, Cosic I (2010) Factors influencing uncertainty in measurement of electric fields close to the body in personal RF dosimetry Radiat Prot Dosimetry 140:25-33 doi:10.1093/rpd/ncp309

Joseph W, Vermeeren G, Verloock L, Heredia MM, Martens L (2008) Characterization of personal RF electromagnetic field exposure and actual absorption for the general public Health Phys 95:317-330 doi:10.1097/01.hp.0000318880.16023.61

Juhasz P, Bakos J, Nagy N, Janossy G, Finta V, Thuroczy G (2011) RF personal exposimetry on employees of elementary schools, kindergartens and day nurseries as a proxy for child exposures Prog Biophys Mol Biol 107:449-455 doi:10.1016/j.pbiomolbio.2011.09.020

Lauer O, Frei P, Gosselin MC, Joseph W, Röösli M, Fröhlich J (2013) Combining near- and far-field exposure for an organ-specific and whole-body RF-EMF proxy for epidemiological research: a reference case Bioelectromagnetics 34:366-374 doi:10.1002/bem.21782

Lauer O, Leidenberger, P., Müri, M., Zahner, M., Fröhlich, J. (2011) A Novel Measurement System for Environmental Exposure Monitoring. Paper presented at the ACM SenSys 2011, Seattle, WA, USA,

Lauer O, Neubauer G, Röösli M, Riederer M, Frei P, Mohler E, Fröhlich J (2012) Measurement setup and protocol for characterizing and testing radio frequency personal exposure meters Bioelectromagnetics 33:75-85 doi:10.1002/bem.20687

Neubauer G, Cecil S, Giczi W, Petric B, Preiner P, Fröhlich J, Röösli M (2010) The association between exposure determined by radiofrequency personal exposimeters and human exposure: a simulation study Bioelectromagnetics 31:535-545 doi:10.1002/bem.20587 
Persson T, Tornevik C, Larsson LE, Loven J (2012) Output power distributions of terminals in a $3 \mathrm{G}$ mobile communication network Bioelectromagnetics 33:320-325 doi:10.1002/bem.20710

Röösli M, Frei P, Bolte J, Neubauer G, Cardis E, Feychting M, Gajsek P, Heinrich S, Joseph W, Mann S et al. (2010) Conduct of a personal radiofrequency electromagnetic field measurement study: proposed study protocol Environ Health 9:23 doi:10.1186/1476069x-9-23

Roser K, Schoeni A, Bürgi A, Röösli M (2015a) Development of an RF-EMF Exposure Surrogate for Epidemiologic Research International Journal of Environmental Research and Public Health 12:5634-5656

Roser K, Schoeni A, Foerster M, Röösli M (2015b) Problematic mobile phone use of Swiss adolescents: is it linked with mental health or behaviour? Int J Public Health doi:10.1007/s00038-015-0751-2

Roser K, Schoeni A, Roosli M (2016) Mobile phone use, behavioural problems and concentration capacity in adolescents: A prospective study Int J Hyg Environ Health 219:759-769 doi:10.1016/j.ijheh.2016.08.007

Schoeni A, Roser K, Burgi A, Röösli M (2016) Symptoms in Swiss adolescents in relation to exposure from fixed site transmitters: a prospective cohort study Environ Health 15:77 doi:10.1186/s12940-016-0158-4

Schoeni A, Roser K, Röösli M (2015a) Memory performance, wireless communication and exposure to radiofrequency electromagnetic fields: A prospective cohort study in adolescents Environ Int 85:343-351 doi:10.1016/j.envint.2015.09.025

Schoeni A, Roser K, Röösli M (2015b) Symptoms and Cognitive Functions in Adolescents in Relation to Mobile Phone Use during Night PLoS One 10:e0133528 doi:10.1371/journal.pone.0133528

SEAWIND Sound Exposure \& Risk Assessment of Wireless Network Devices Final Summary Report (2013). http://seawind-fp7.eu/uploads/SEAWIND_FINAL.pdf

Thomas S, Kuhnlein A, Heinrich S, Praml G, Nowak D, von Kries R, Radon K (2008a) Personal exposure to mobile phone frequencies and well-being in adults: a crosssectional study based on dosimetry Bioelectromagnetics 29:463-470 doi:10.1002/bem.20414

Thomas S, Kuhnlein A, Heinrich S, Praml G, von Kries R, Radon K (2008b) Exposure to mobile telecommunication networks assessed using personal dosimetry and well-being in children and adolescents: the German MobilEe-study Environ Health 7:54 doi:10.1186/1476-069x-7-54

Thuróczy G, Molnár F, Jánossy G, Nagy N, Kubinyi G, Bakos J, Szabó † J (2008) Personal $\mathrm{RF}$ exposimetry in urban area annals of telecommunications - annales des télécommunications 63:87-96 doi:10.1007/s12243-007-0008-z

Tomitsch J, Dechant E (2015) Exposure to electromagnetic fields in households--trends from 2006 to 2012 Bioelectromagnetics 36:77-85 doi:10.1002/bem.21887

Tomitsch J, Dechant E, Frank W (2010) Survey of electromagnetic field exposure in bedrooms of residences in lower Austria Bioelectromagnetics 31:200-208 doi:10.1002/bem.20548

Urbinello D, Joseph W, Verloock L, Martens L, Röösli M (2014) Temporal trends of radiofrequency electromagnetic field (RF-EMF) exposure in everyday environments across European cities Environ Res 134:134-142 doi:10.1016/j.envres.2014.07.003

Urbinello D, Röösli M (2013) Impact of one's own mobile phone in stand-by mode on personal radiofrequency electromagnetic field exposure J Expo Sci Environ Epidemiol 23:545-548 doi:10.1038/jes.2012.97

Valic B, Kos B, Gajsek P (2015) Typical exposure of children to EMF: exposimetry and dosimetry Radiat Prot Dosimetry 163:70-80 doi:10.1093/rpd/ncu057 
Valic B, Trcek T, Gajsek P (2009) Personal exposure to high frequency electromagnetic fields in Slovenia. Paper presented at the Joint Meeting of the Bioelectromagnetics Society and the European Bio Electromagnetics Association, Davos, Switzerland, 14-19 June 2009

Verloock L, Joseph W, Goeminne F, Martens L, Verlaek M, Constandt K (2014a) Assessment of radio frequency exposures in schools, homes, and public places in Belgium Health Phys 107:503-513 doi:10.1097/hp.0000000000000149

Verloock L, Joseph W, Goeminne F, Martens L, Verlaek M, Constandt K (2014b) Temporal 24-hour assessment of radio frequency exposure in schools and homes Measurement 56:50-57 doi:http://dx.doi.org/10.1016/j.measurement.2014.06.012

Vermeeren G, Markakis I, Goeminne F, Samaras T, Martens L, Joseph W (2013) Spatial and temporal RF electromagnetic field exposure of children and adults in indoor micro environments in Belgium and Greece Prog Biophys Mol Biol 113:254-263 doi:10.1016/j.pbiomolbio.2013.07.002

Viel JF, Cardis E, Moissonnier M, de Seze R, Hours M (2009) Radiofrequency exposure in the French general population: band, time, location and activity variability Environ Int 35:1150-1154 doi:10.1016/j.envint.2009.07.007

WHO (2010) WHO Research Agenda for Radiofrequency Fields.

Willemse I, Waller G, Süss D (2014) JAMES Jugend, Aktivitäten, Medien - Erhebung Schweiz, Factsheet Befunde 2014. Zurich University of Applied Sciences. 
Table 1: Frequency range and reporting limit of the used frequency bands measured by the ExpoM-RF exposimeter (the current version and a not commercialized prototype). The sum of these bands is named total personal RF-EMF measurements.

\begin{tabular}{|c|c|c|c|c|}
\hline Frequency band & description & $\begin{array}{c}\text { frequency } \\
\text { range } \\
\text { [MHz] }\end{array}$ & $\begin{array}{c}\text { lower } \\
\text { reporting } \\
\text { limit }[\mathrm{V} / \mathrm{m}]\end{array}$ & $\begin{array}{c}\text { upper } \\
\text { reporting } \\
\text { limit }[V / m]\end{array}$ \\
\hline TV & Television broadcast transmitter & $470-790$ & 0.0025 & 5 \\
\hline LTE 800 Downlink ${ }^{1}$ & Transmission from mobile phone base station to handset & $791-821$ & 0.0025 & 5 \\
\hline LTE 800 Uplink $^{1}$ & Transmission from mobile phone handset to base station & $832-862$ & 0.0025 & 5 \\
\hline Uplink $900^{2}$ & Transmission from mobile phone handset to base station & $880-915$ & 0.0025 & 5 \\
\hline Downlink $900^{3}$ & Transmission from mobile phone base station to handset & $925-960$ & 0.0025 & 5 \\
\hline Uplink $1800^{2}$ & Transmission from mobile phone handset to base station & $1710-1785$ & 0.0025 & 5 \\
\hline Downlink $1800^{3}$ & Transmission from mobile phone base station to handset & $1805-1880$ & 0.0025 & 5 \\
\hline DECT & Digital Enhanced Cordless Telecommunications & $1880-1900$ & 0.0025 & 5 \\
\hline Uplink $1900^{2}$ & Transmission from mobile phone handset to base station & $1920-1980$ & 0.0015 & 5 \\
\hline Downlink $2100^{3}$ & Transmission from mobile phone base station to handset & $2110-2170$ & 0.0015 & 5 \\
\hline LTE $2600^{1}$ & $\begin{array}{l}\text { Transmission from mobile phone base station to handset } \\
\text { and vice versa (combined downlink and uplink) }\end{array}$ & $2500-2690$ & 0.0125 & 5 \\
\hline WLAN & Wireless Local Area Network & $2400-2485$ & 0.0025 & 5 \\
\hline
\end{tabular}

${ }^{1}$ Belongs to the total RF-EMF, but is not considered for the frequency band specific analyses.

${ }^{2}$ Belongs to the summarized uplink band; Uplink = Uplink $900+$ Uplink $1800+$ Uplink 1900.

${ }^{3}$ Belongs to the summarized downlink band; Downlink = Downlink $900+$ Downlink 1800 + Downlink 2100. 
Table 2: Characteristics of the personal measurements sample $(\mathrm{n}=90)$ and the HERMES cohort $(n=425)$ and $p$-value for the $t$ test statistics for age and for the $\chi^{2}$ test statistics for the other characteristics (significant results $(\mathrm{p}<0.05)$ are indicated in bold).

\begin{tabular}{|c|c|c|c|c|c|c|c|}
\hline & \multicolumn{3}{|c|}{ Personal measurements $(n=90)$} & \multicolumn{3}{|c|}{ HERMES cohort $(n=425)$} & \multirow[b]{2}{*}{$p$-value $\chi^{2}$} \\
\hline & $\mathbf{n}$ & Number & Percentage (\%) & $\mathrm{n}^{*}$ & Number & Percentage (\%) & \\
\hline \multicolumn{8}{|l|}{ Personal characteristics } \\
\hline Age (years) & 90 & \multicolumn{2}{|c|}{$15.1(13.2-17.2)$} & 425 & \multicolumn{2}{|c|}{$15.0(13.2-17.8)$} & 0.80 (t-test) \\
\hline Sex: female & 90 & 57 & 63.3 & 425 & 254 & 59.8 & 0.44 \\
\hline School level: college preparatory high school & 90 & 21 & 23.3 & & 97 & 22.8 & 0.90 \\
\hline Nationality & & & & & & & 0.01 \\
\hline Swiss & & 81 & 90.0 & & 341 & 80.2 & \\
\hline Mixed & & 4 & 4.4 & & 59 & 13.9 & \\
\hline Foreign & & 5 & 5.6 & & 25 & 5.9 & \\
\hline \multicolumn{8}{|l|}{ WLAN at school and at home } \\
\hline WLAN at school & 90 & 34 & 37.8 & 425 & 168 & 39.5 & 0.70 \\
\hline WLAN at home & 90 & 86 & 95.6 & 342 & 319 & 93.3 & 0.31 \\
\hline Not switching off WLAN at home & 86 & 61 & 70.9 & 310 & 208 & 67.1 & 0.37 \\
\hline \multicolumn{8}{|l|}{ Mobile phone use } \\
\hline Owning a mobile phone & 90 & 90 & 100.0 & 425 & 416 & 97.9 & 0.12 \\
\hline Owning a smartphone & 90 & 85 & 94.4 & 416 & 398 & 95.7 & 0.52 \\
\hline Having a mobile phone subscription & 90 & 41 & 45.6 & 416 & 234 & 56.3 & 0.01 \\
\hline Mobile phone switched off during night & 90 & & & 413 & & & 0.13 \\
\hline No (Almost never or never/Sometimes) & & 66 & 73.3 & & 270 & 65.4 & \\
\hline Yes (Frequently/Almost always or always) & & 24 & 26.7 & & 143 & 34.6 & \\
\hline Using mobile internet on the mobile phone & 90 & 83 & 92.2 & 415 & 387 & 93.3 & 0.66 \\
\hline Use WLAN for internet on the mobile phone & 83 & & & 385 & & & 0.10 \\
\hline Yes (About half of the time/Always) & & 69 & 83.1 & & 340 & 88.3 & \\
\hline No (No/Sometimes) & & 14 & 16.9 & & 45 & 11.7 & \\
\hline
\end{tabular}

* Missing values in the HERMES cohort: 83 for WLAN at home, 9 for Not switching off WLAN at home, 3 for Mobile phone switched off during night, 1 for Using mobile internet on the mobile phone and 2 for Use WLAN for internet on the mobile phone. 
Table 3: Summary statistics for the whole measurement period per frequency band, for uplink, downlink and total RF-EMF measurements $\left(\mu \mathrm{W} / \mathrm{m}^{2}\right)$ and total RF-EMF measurements in $\mathrm{V} / \mathrm{m}$.

\begin{tabular}{lccccccccc}
\hline $\begin{array}{l}\text { Frequency } \\
\text { band }\end{array}$ & \multicolumn{2}{c}{ mean (\%) } & min & $\begin{array}{c}\text { 5th } \\
\text { percentile }\end{array}$ & $\begin{array}{c}\text { 25th } \\
\text { percentile }\end{array}$ & median & $\begin{array}{c}\text { 75th } \\
\text { percentile }\end{array}$ & $\begin{array}{c}\text { 95th } \\
\text { percentile }\end{array}$ & max \\
\hline TV & 4.26 & $(6.7)$ & 0.08 & 0.13 & 0.41 & 0.62 & 2.33 & 11.84 & 169.78 \\
Uplink 900 & 24.59 & $(38.9)$ & 0.02 & 0.20 & 1.38 & 6.03 & 27.54 & 88.17 & 263.61 \\
Downlink 900 & 9.40 & $(14.9)$ & 0.19 & 0.35 & 1.38 & 3.33 & 10.35 & 44.61 & 103.24 \\
Uplink 1800 & 7.23 & $(11.4)$ & 0.02 & 0.08 & 0.19 & 0.44 & 1.81 & 17.46 & 327.07 \\
Downlink 1800 & 1.42 & $(2.3)$ & 0.04 & 0.07 & 0.23 & 0.62 & 1.39 & 4.96 & 19.45 \\
DECT & 0.83 & $(1.3)$ & 0.02 & 0.02 & 0.02 & 0.07 & 0.36 & 3.99 & 14.71 \\
Uplink 1900 & 10.67 & $(16.9)$ & 0.01 & 0.01 & 0.06 & 0.81 & 4.24 & 30.45 & 373.49 \\
Downlink 2100 & 1.67 & $(2.6)$ & 0.03 & 0.04 & 0.15 & 0.43 & 1.87 & 6.85 & 17.19 \\
WLAN $^{2.18}$ & $(3.5)$ & 0.03 & 0.05 & 0.24 & 0.56 & 1.72 & 11.63 & 23.88 \\
\hline Uplink $^{1}$ & 42.49 & $(67.2)$ & 0.07 & 0.38 & 2.51 & 12.15 & 39.64 & 177.22 & 664.88 \\
Downlink $^{2}$ & 12.50 & $(19.8)$ & 0.34 & 0.62 & 2.12 & 5.07 & 13.47 & 51.36 & 107.99 \\
\hline Total $^{3}$ & 63.23 & & 1.78 & 5.92 & 11.34 & 25.49 & 70.86 & 240.41 & 682.90 \\
\hline & & & & & & & & & 0.16 \\
\hline Total $^{3}$ [V/m] & 0.15 & & 0.03 & 0.05 & 0.07 & 0.10 & 0.16 & 0.30 & \\
\hline
\end{tabular}

${ }^{1}$ Uplink = Uplink $900+$ Uplink $1800+$ Uplink 1900.

${ }^{2}$ Downlink $=$ Downlink $900+$ Downlink $1800+$ Downlink 2100.

${ }^{3}$ Total refers to the total RF-EMF measurements considering the twelve frequency bands listed in Table 1. 
Table 4: Comparison with other personal measurements studies.

\begin{tabular}{|c|c|c|c|c|c|c|c|c|c|c|c|}
\hline \multirow[t]{2}{*}{ Country } & \multirow[t]{2}{*}{$\begin{array}{l}\text { Sample } \\
\text { size }\end{array}$} & \multirow[t]{2}{*}{$\begin{array}{l}\text { study } \\
\text { population }\end{array}$} & \multirow[t]{2}{*}{ measurement period } & \multirow[t]{2}{*}{ exposimeter } & \multirow[t]{2}{*}{ additional information } & \multicolumn{5}{|c|}{ 24h exposure $\left[\mu \mathrm{W} / \mathrm{m}^{2}\right]$} & \\
\hline & & & & & & Total & Uplink & Downlink & DECT & WLAN & \\
\hline Switzerland & 90 & adolescents & May 2013 - April 2014 & ExpoM-RF & $\begin{array}{l}\text { - Exposimeter carried in a padded } \\
\text { hip bag when moving, in their } \\
\text { vicinity when not moving } \\
\text { - DECT correction algorithm } \\
\text { applied } \\
\text { - Exposimeter worn on belt or in }\end{array}$ & 63.2 & 42.5 & 12.5 & 0.8 & 2.2 & HERMES \\
\hline Switzerland & 166 & adults & April 2007 - February 2008 & $\begin{array}{l}\text { EME Spy } \\
120\end{array}$ & $\begin{array}{l}\text { backpack when moving, in their } \\
\text { vicinity when not moving } \\
\text { - Mobile phone and cordless phone } \\
\text { calls excluded } \\
\text { - Reporting limit }=6.6 \mu \mathrm{W} / \mathrm{m}^{2} \text {; ROS } \\
\text { method for non-detects applied } \\
\text { (Helsel 2005) }\end{array}$ & 130 & 37.9 & 41.6 & 29.5 & 5.3 & $\begin{array}{l}\text { (Frei et al. } \\
\text { 2009) }\end{array}$ \\
\hline Hungary & 21 & adults & June - July 2005 & DSP-090 & $\begin{array}{l}\text { - Exposimeter worn on the body } \\
\text { when moving, in their vicinity when } \\
\text { not moving } \\
\text { - Reporting limit }=6.6 \mu \mathrm{W} / \mathrm{m}^{2} \text {; non- } \\
\text { detects set to reporting limit }\end{array}$ & 70.3 & 23.8 & 24.2 & - & - & $\begin{array}{l}\text { (Thuróczy } \\
\text { et al. } \\
\text { 2008) }\end{array}$ \\
\hline Germany & 3000 & $\begin{array}{l}\text { children and } \\
\text { adolescents }\end{array}$ & $\begin{array}{l}\text { February } 2006 \text { - December } \\
2007\end{array}$ & ESM-140 & $\begin{array}{l}\text { - Exposimeter worn on arm } \\
\text { - No differentiation between uplink } \\
\text { and downlink possible due to } \\
\text { exposimeter limitations } \\
\text { - Only daytime data } \\
\text { - Reporting limit }=6.6 \mu \mathrm{W} / \mathrm{m}^{2} \text {; non- } \\
\text { detects set to reporting limit/2 }\end{array}$ & 22.8 & - & - & - & - & $\begin{array}{l}\text { (Thomas } \\
\text { et al. } \\
\text { 2008b) }\end{array}$ \\
\hline
\end{tabular}




\begin{tabular}{|c|c|c|c|c|c|c|c|c|c|c|c|}
\hline Germany & 329 & adults & $\begin{array}{l}\text { January } 2005 \text { - August } \\
2006\end{array}$ & ESM-140 & $\begin{array}{l}\text { - Exposimeter worn on arm } \\
\text { - No differentiation between uplink } \\
\text { and downlink possible due to } \\
\text { measurement device limitations } \\
\text { - Only daytime data } \\
\text { - Reporting limit }=6.6 \mu \mathrm{W} / \mathrm{m}^{2} ; \text { non- } \\
\text { detects set to reporting limit } / 2\end{array}$ & 24.0 & - & - & - & 1.1 & $\begin{array}{l}\text { (Thomas } \\
\text { et al. } \\
\text { 2008a) }\end{array}$ \\
\hline $\begin{array}{l}\text { The } \\
\text { Netherlands }\end{array}$ & 98 & adults & 2009 & $\begin{array}{l}\text { EME Spy } \\
121\end{array}$ & $\begin{array}{l}\text { - Exposimeter worn on right hip at } \\
\text { fixed angle } \\
\text { - Mobile phone and cordless phone } \\
\text { calls excluded } \\
\text { - Reporting limit }=6.6 \mu \mathrm{W} / \mathrm{m}^{2} \text {; ROS } \\
\text { method for non-detects applied } \\
\text { (Helsel 2005) }\end{array}$ & 180.0 & 67.5 & 22.9 & 57.1 & 25.4 & $\begin{array}{l}\text { (Bolte and } \\
\text { Eikelboom } \\
\text { 2012) }\end{array}$ \\
\hline Slovenia & 18 & $\begin{array}{l}\text { children and } \\
\text { adolescents }\end{array}$ & $\begin{array}{l}\text { February } 2010 \text { - March } \\
2011\end{array}$ & $\begin{array}{l}\text { EME Spy } \\
120\end{array}$ & $\begin{array}{l}\text { - Reporting limit }=6.6 \mu \mathrm{W} / \mathrm{m}^{2} ; \text { non- } \\
\text { detects set to reporting limit }\end{array}$ & $75.2^{1}$ & - & 26.2 & 13 & 9.6 & $\begin{array}{l}\text { (Valic et } \\
\text { al. 2015) }\end{array}$ \\
\hline France & 377 & adults & $\begin{array}{l}\text { December } 2005 \text { - } \\
\text { September } 2006\end{array}$ & $\begin{array}{l}\text { EME Spy } \\
120\end{array}$ & $\begin{array}{l}\text { - Exposimeter worn on body (waist } \\
\text { or over shoulder) when moving, in } \\
\text { their vicinity during night } \\
\text { - Reporting limit }=6.6 \mu \mathrm{W} / \mathrm{m}^{2} \text {; ROS } \\
\text { method for non-detects applied } \\
\text { (Helsel 2005) }\end{array}$ & $22.7^{2}$ & 4.3 & 5.1 & 3.6 & 3.8 & $\begin{array}{l}\text { (Viel et al. } \\
\text { 2009) }\end{array}$ \\
\hline Slovenia & 54 & adults & $\begin{array}{l}\text { July } 2007 \text { - November } \\
2008\end{array}$ & $\begin{array}{l}\text { EME Spy } \\
120\end{array}$ & $\begin{array}{l}\text { - Exposimeter worn on the belt, in } \\
\text { pouch or backpack when moving, in } \\
\text { their vicinity when not moving } \\
\text { - Reporting limit }=6.6 \mu \mathrm{W} / \mathrm{m}^{2} \text {; non- } \\
\text { detects set to reporting limit }\end{array}$ & - & 25.7 & 42.1 & 8.2 & 7.7 & $\begin{array}{l}\text { (Valic et } \\
\text { al. 2009) }\end{array}$ \\
\hline
\end{tabular}

${ }^{1}$ Total without uplink since exposure to mobile phones was not evaluated in the study.

${ }^{2}$ Own calculation of the sum of all frequency bands for the Total. The original paper reports a Total of $107.2 \mu \mathrm{W} / \mathrm{m}^{2}$, which does not fit the sum of the frequency bands. 
Figure 1: Participants of the personal measurements consisting of a subgroup of the participants of the HERMES cohort.

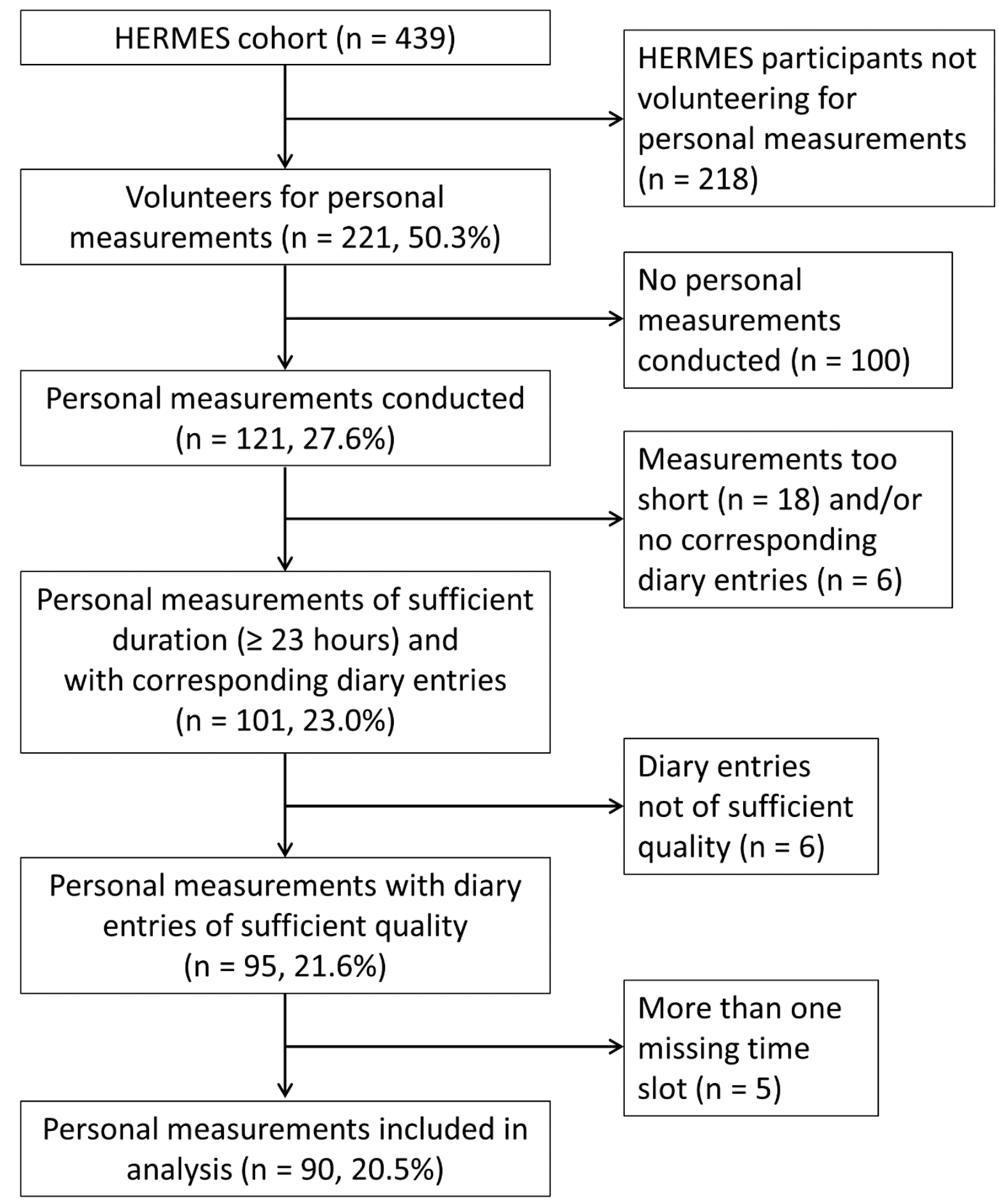


Figure 2: Mean contributions of different sources to the total personal RF-EMF measurements (in power flux density). Mean $=63.2 \mu \mathrm{W} / \mathrm{m}^{2}(0.15 \mathrm{~V} / \mathrm{m}$ ).

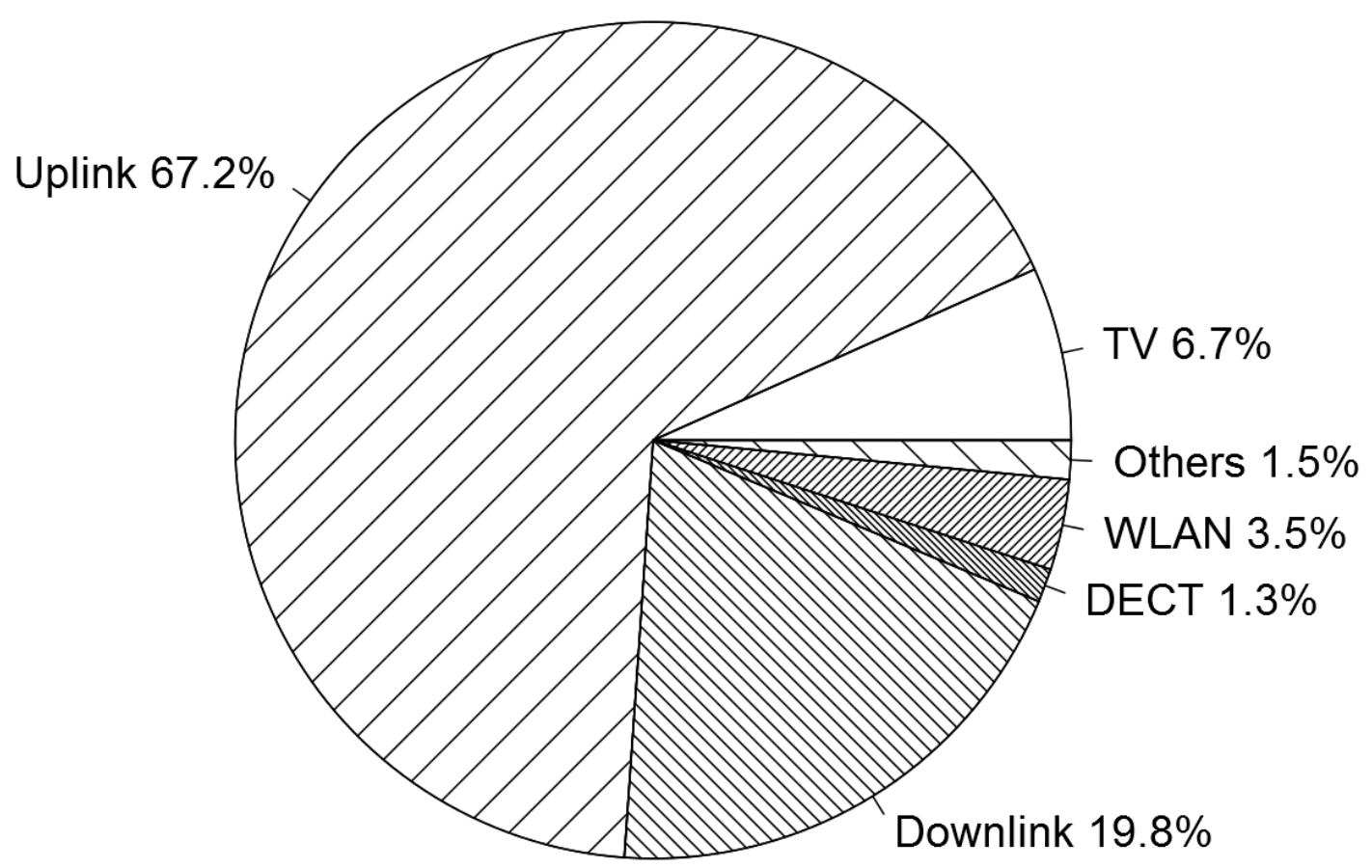

Others refers to the frequency bands LTE 800 Downlink, LTE 800 Uplink and LTE 2600. 
Figure 3: Mean RF-EMF measurements from different sources at different locations. The hours in brackets indicate cumulative measurement duration at the corresponding location, $\mathrm{n}$ indicates the number of participants with measurements assigned to the location according to the diary. Total mean RF-EMF measurements at the locations are additionally added in $\mathrm{V} / \mathrm{m}$. The corresponding numbers and median values can be found in Tables S1 and S2 in the Supplementary Material.

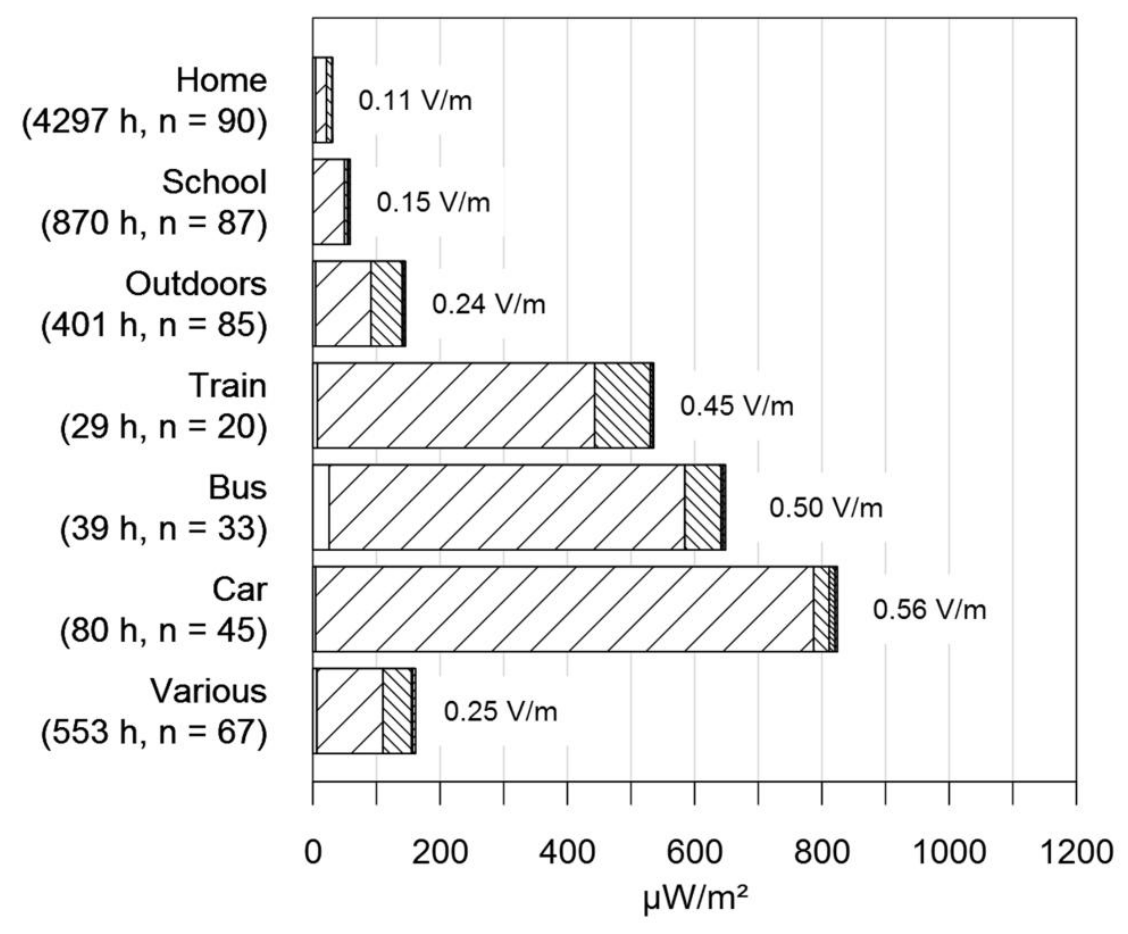

$\square$ TV $\quad \square$ Uplink $\quad$ Downlink $\quad \mathbb{E}$ DECT $\quad$ WLAN 
Figure 4: Mean RF-EMF measurements for all participants $(\mathrm{n}=90)$ and mean measurements for No WLAN at home $(\mathrm{n}=4)$, WLAN at home only $(\mathrm{n}=54)$ and WLAN at home and in school $(\mathrm{n}=32)$. Total mean RF-EMF measurements per group are additionally added in $\mathrm{V} / \mathrm{m}$. The corresponding numbers and median values can be found in Tables S3 and S4 the the Supplementary Material.

All participants $(n=90)$

No WLAN at home

$$
(n=4)
$$

WLAN at home only $(n=54)$

WLAN at home and at school $(n=32)$

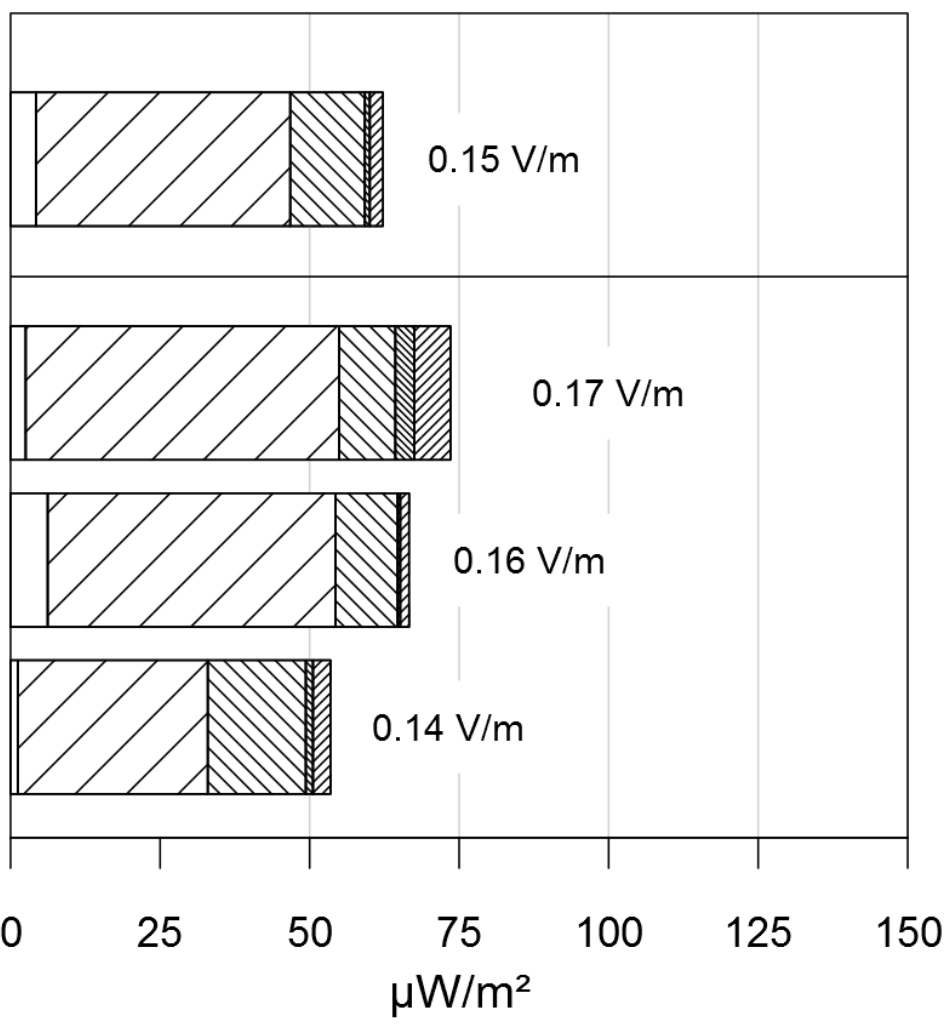


Figure 5: Mean RF-EMF measurements for all participants and mean RF-EMF measurements for the mobile phone related factors having a mobile phone subscription (compared to using a prepaid mobile phone), not switching off the mobile phone during the night and the use of internet on the mobile phone (with and without WLAN). Total mean RF-EMF measurements per group are additionally added in $\mathrm{V} / \mathrm{m}$. The corresponding numbers and median values can be found in Tables S5 and S6 in the Supplementary Material.

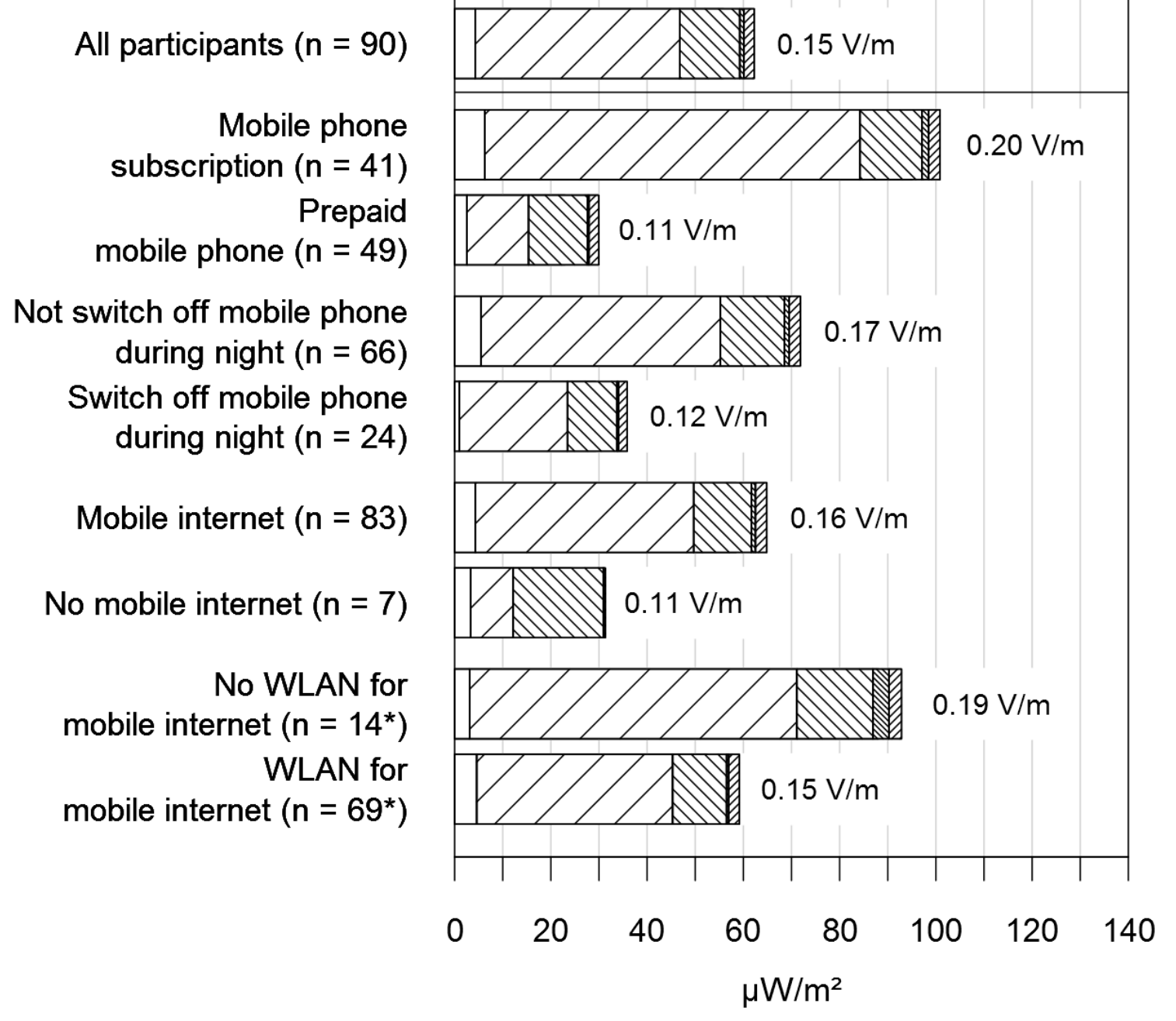

* Note, that the groups No WLAN for mobile internet and WLAN for mobile internet include only participants using mobile internet on the mobile phone $(\mathrm{n}=83)$. 
Figure 6: Diurnal variation of mean RF-EMF measurements: For daytime and night-time ( $\mathrm{n}=$ 90) and for workdays and weekend $(n=38)$ for different RF-EMF sources. Total mean RFEMF measurements per time of the day and type of day are additionally added in $\mathrm{V} / \mathrm{m}$. The corresponding numbers and median values can be found in Tables S7 and S8 in the Supplementary Material.

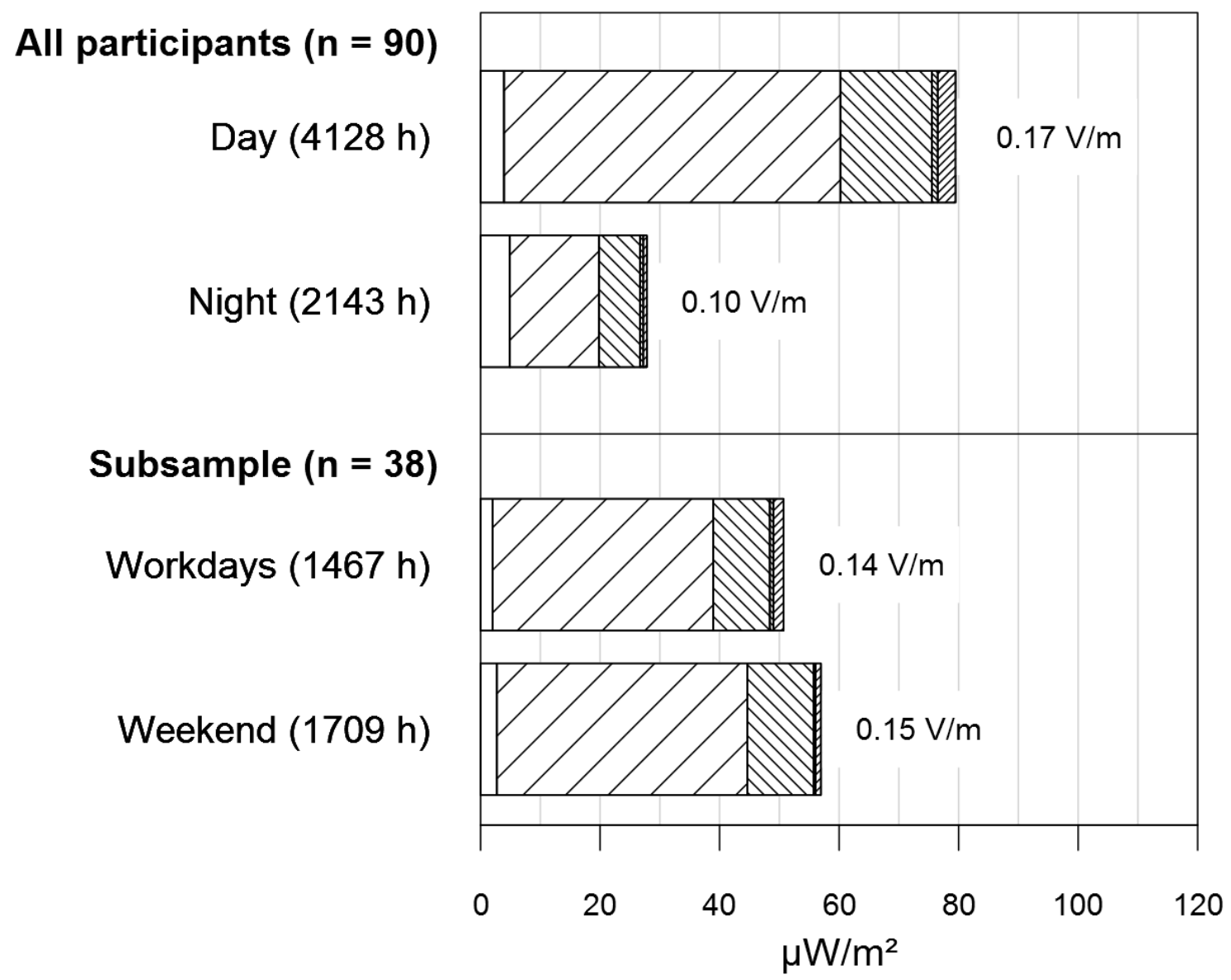


Figure 7: Diurnal variation of the mean total RF-EMF measurements on workdays (white bars) and on weekends (shaded bars) based on data from the subsample of 38 participants with workdays and weekend measurements available. The corresponding numbers and median values can be found in Tables S9 in the Supplementary Material.

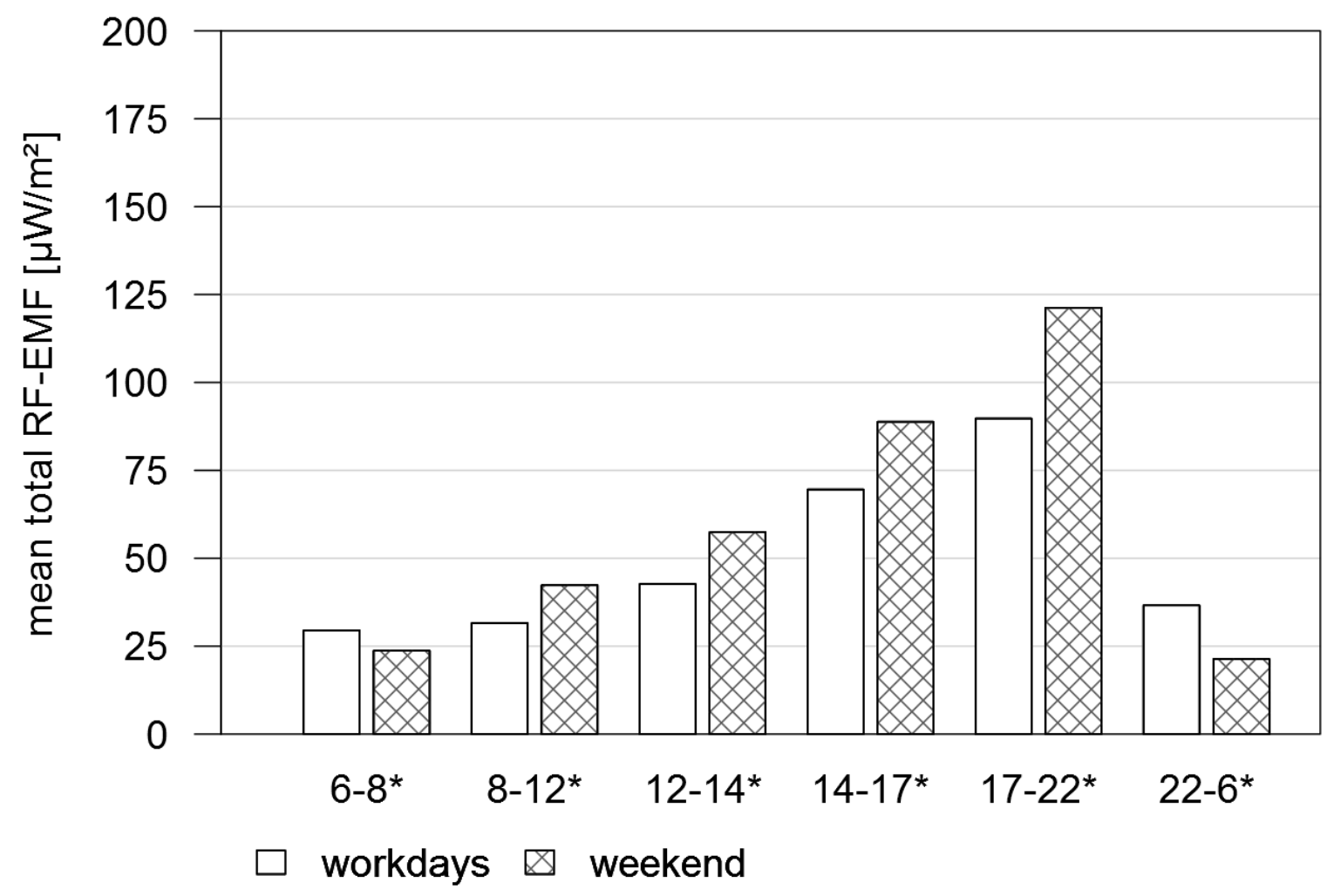

* Note that these time slots correspond to the time slots 06:00-07:59, 08:00-11:59, 12:0013:59, 14:00-16:59, 17:00-21:59, and 22:00-05:59. 
Figure 8: Daily brain dose from the use of wireless communication devices (near-field dose; left side of the graph) and environmental sources (far-field dose; right side of the graph) for the typical (average) HERMES participant.* Numbers above the bars indicate the percentage of the near-field and the far-field dose on the total dose, respectively.

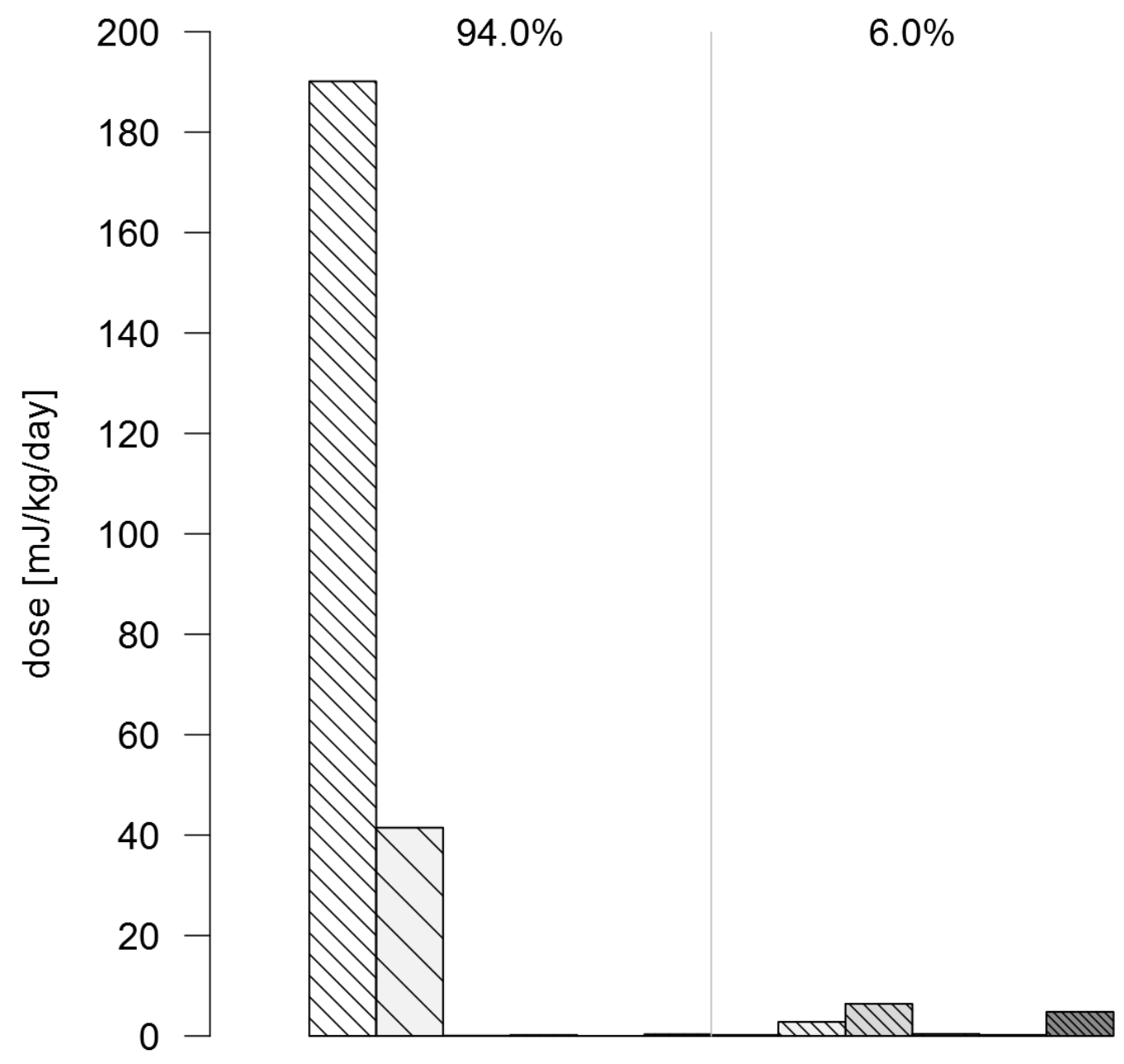

\begin{tabular}{|c|c|c|c|}
\hline & Near-field & & Far-field \\
\hline$\triangle$ & Mobile phone calls & $\square$ & Radio \\
\hline$\nabla$ & DECT phone calls & $\Delta$ & TV \\
\hline$\square$ & Mobile phone data traffic network & 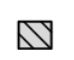 & Downlink \\
\hline 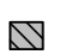 & Mobile phone data traffic WLAN & $\square$ & WLAN \\
\hline$\square$ & Stand-by mobile phone data traffic & $\square$ & DECT \\
\hline & Computer, laptop and tablet use with WLAN & $\mathbb{Q}$ & Uplink \\
\hline
\end{tabular}

* Average daily device use in HERMES: 1.85 min mobile phone and DECT phone calls, 11.5 min of mobile phone data traffic via network and 30.6 min via WLAN, 57.6 min of computer, laptop and tablet use while connected to WLAN and having the mobile phone on the body for $4.42 \mathrm{~h}$. 
Figure 9: Daily whole body dose from the use of wireless communication devices (near-field dose; left side of the graph) and environmental sources (far-field dose; right side of the graph) for the typical (average) HERMES participant.* Numbers above the bars indicate the percentage of the near-field and the far-field dose on the total dose, respectively.

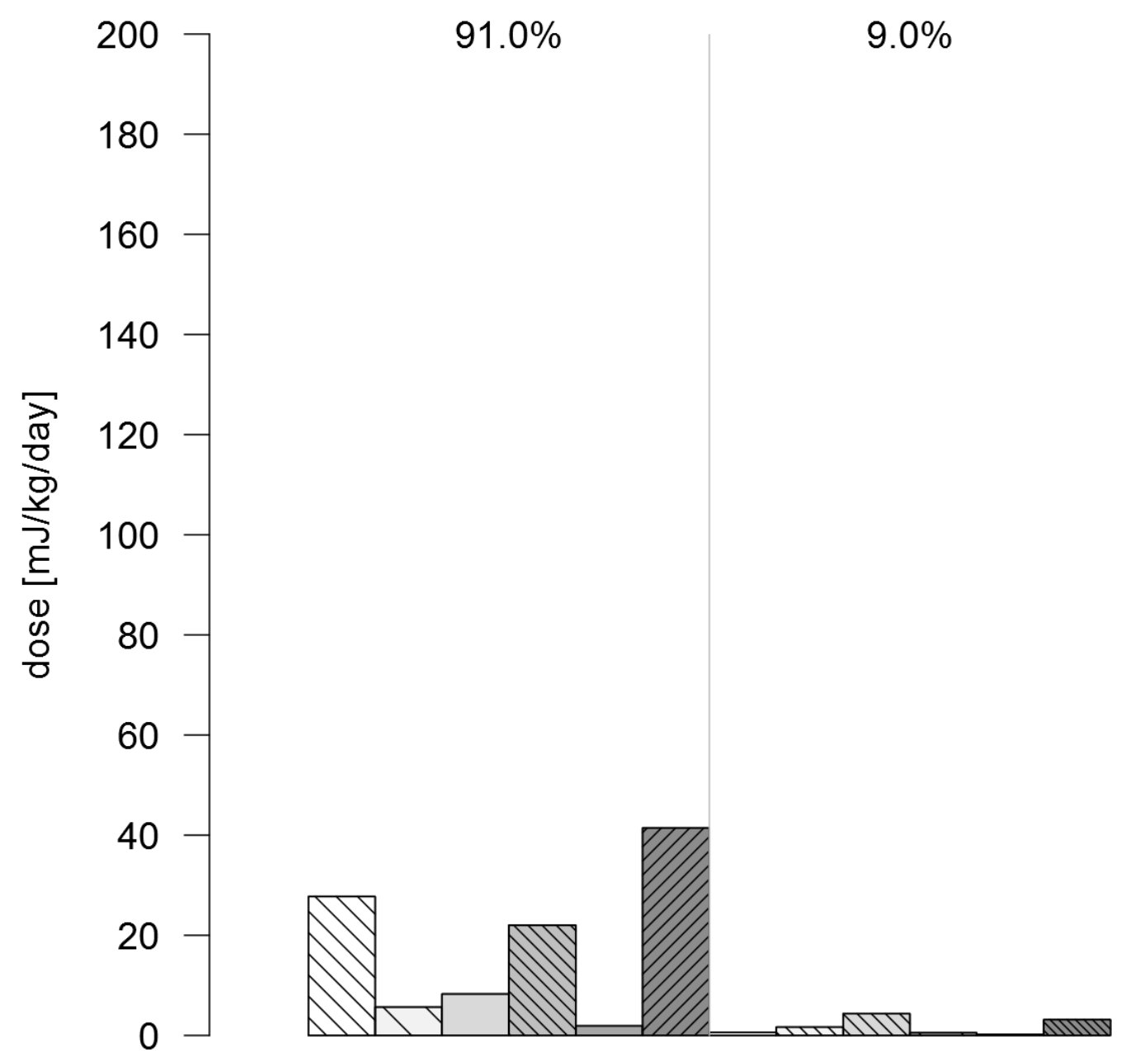

\begin{tabular}{|c|c|c|c|}
\hline & Near-field & & Far-field \\
\hline$\triangle$ & Mobile phone calls & $\square$ & Radio \\
\hline$\nabla$ & DECT phone calls & $\Delta$ & TV \\
\hline$\square$ & Mobile phone data traffic network & $\Delta$ & Downlink \\
\hline$\Phi$ & Mobile phone data traffic WLAN & $\square$ & WLAN \\
\hline Z & Stand-by mobile phone data traffic & $\square$ & DECT \\
\hline 77 & Computer, laptop and tablet use with WLAN & $\mathbb{\mathbb { N }}$ & Uplink \\
\hline
\end{tabular}

* Average daily device use in HERMES: 1.85 min mobile phone and DECT phone calls, 11.5 min of mobile phone data traffic via network and 30.6 min via WLAN, 57.6 min of computer, laptop and tablet use while connected to WLAN and having the mobile phone on the body for $4.42 \mathrm{~h}$. 